\title{
OPEN Novel cationic aryl bithiophene/ terthiophene derivatives as corrosion inhibitors by chemical, electrochemical and surface investigations
}

\author{
Mohamed A. Ismail ${ }^{1 凶}$, Mahmoud M. Shaban ${ }^{2}$, Ehab Abdel-Latif ${ }^{1}$, Fatma H. Abdelhamed ${ }^{1}$, \\ Mohamed A. Migahed ${ }^{2}$, Mahmoud N. El-Haddad ${ }^{1}$ \& Ashraf S. Abousalem ${ }^{1,3} \bowtie$
}

Two novel bithienyl fluorobenzamidine derivatives namely, 4-([2,2':5',2'-terthiophen]-5-yl)-2fluorobenzamidine hydrochloride salt (MA-1615), 5'-(4-amidino-3-fluorophenyl)-[2,2'-bithiophene]5-carboxamidine dihydrochloride salt (MA-1740) were synthesized, characterized and their corrosion inhibition properties were evaluated by electrochemical methods for carbon steel (C-steel) in $1 \mathrm{M}$ $\mathrm{HCl}$. Experimental investigations revealed that the inhibition effectiveness of the investigated inhibitors (INHs) by the Tafel polarization method followed the order: MA-1740 (96.9\%) > MA-1615 (95.6\%), demonstrating higher efficiency than inhibitors of similar structure reported in the literature. The investigated bithiophene derivatives exhibit mixed-type corrosion inhibition characteristics by blocking the active sites on the surface of C-steel. EIS study revealed that the INHs behave as interface-type corrosion inhibitors. UV-Visible spectrometric measurements confirmed a complex formation between the $\mathrm{Fe}^{2+}$ cation released during the corrosion reactions and inhibitor molecules.

Corrosion is commonly defined as the degradation of materials as a result of interaction with the surrounding environment. It occurs to metallic materials when exposed to corrosive environments, causing destructive industrial problems that result in a huge economic loss for many countries around the world. Not only does corrosion cause huge material loss, but also compromise human safety ${ }^{1,2}$. Despite the large number of ongoing research projects that aimed to design new corrosion resistant materials to cater for different types of industrial applications, C-steel is still the black horse among other metals due to its versatility, cost effectiveness, and excellent mechanical properties. However, one main drawback of using it in industries is that it easily corrodes when exposed to aggressive acids such as hydrochloric acid, which is widely used in oil and gas operations such as pickling, cleaning, and oil-well acidizing ${ }^{3}$. Nowadays, investigating the inhibitory performance of C-steel corrosion in such acid medium has received a considerable attention in academia and across the industrial domain. Over the last three decades, there have been some studies devoted to the development of efficient and costeffective corrosion inhibitors. One of the most promising class of inhibitors are those organic compounds with hetero-atoms such as nitrogen, oxygen, sulfur, and phosphorus, which have the ability to adsorb on a metallic surface, and thereby protecting the surface from corrosion attack ${ }^{4}$. Bi- and oligochalcophenes play an important role as advanced materials, which have been applied into numerous fields and applications. These new class of organic compounds can be used as organic semiconductors and radioactive materials due to their luminescent properties $^{5}$. Thiophene-containing cationic compounds are important synthetic precursor for biologically active molecules ${ }^{6-8}$. These types of compounds have significant use in solvatochromic, photosensitizing, and photovoltaic cells applications ${ }^{9-12}$ The idea depends on the presence of donor-( $\pi$-spacer)-acceptor in conjugation with each other consequently ${ }^{13,14}$. These compounds bear cyano group/or cationic amidine group which act as electron withdrawing acceptor, and electron donating group representing in thiophene ring. Owing to growing concerns on the toxic effects of such corrosion inhibitors, ongoing studies are conducted to develop new compounds which have safe impact on environment. The corrosion inhibition performance of bichalcophene compounds have been

\footnotetext{
${ }^{1}$ Department of Chemistry, Faculty of Science, Mansoura University, Mansoura 35516, Egypt. ${ }^{2}$ Egyptian Petroleum Research Institute (EPRI), Nasr City 11727, Cairo, Egypt. ${ }^{3}$ Operation Department, Quality Control Laboratory, Jotun, Egypt. ${ }^{\bowtie}$ email: mismail@mans.edu.eg; ashraf.abousalem@gmail.com
} 


\begin{tabular}{|c|c|c|c|c|c|}
\hline Inhibitor & Material & Media & \%IE & Year & References \\
\hline 4-(2,2'-Bithiophene-5-yl) benzamidine & \multirow{2}{*}{ C-steel } & \multirow{2}{*}{$1 \mathrm{M} \mathrm{HCl}$} & 82.6 & \multirow{2}{*}{2017} & \multirow{2}{*}{18} \\
\hline 6-(2,2'-Bithiophene-5-yl) nicotinamidine & & & 87.7 & & \\
\hline 4-(2,2'-Bifuran-5-yl)benzamidine & \multirow{3}{*}{ C-steel } & \multirow{3}{*}{$1 \mathrm{M} \mathrm{HCl}$} & 66.1 & \multirow{3}{*}{2017} & \multirow{3}{*}{19} \\
\hline 6-(2,2'-Bifuran-5-yl)nicotinamidine & & & 64.5 & & \\
\hline 6-[5-(Thiophen-2-yl)furan-2-yl]nicotinamidine & & & 78.7 & & \\
\hline$\left[2,2^{\prime}: 5^{\prime}, 2^{\prime \prime}\right.$-Terthiophene]-5-amidine & \multirow{4}{*}{ C-steel } & \multirow{4}{*}{$1 \mathrm{M} \mathrm{HCl}$} & 86.6 & \multirow{4}{*}{2019} & \multirow{4}{*}{20} \\
\hline 5'-Phenyl-2,2'-bithiophene-5-amidine & & & 77.9 & & \\
\hline 5'-(4-Methoxyphenyl)-2,2'-bithiophene-5-amidine & & & 80.8 & & \\
\hline 5'-(3,5-Dimethoxyphenyl)-2,2'-bithiophene-5-amidine & & & 83.6 & & \\
\hline 4-([2,2'-Bithiophen]-5-yl)-2-fluorobenzamidine & C-steel & $1 \mathrm{M} \mathrm{HCl}$ & 86.4 & 2019 & 3 \\
\hline 4-([2,2':5',2"-Terthiophen]-5-yl)-2-fluorobenzamidine hydrochloride salt (MA-1615) & \multirow[b]{2}{*}{ C-steel } & \multirow[b]{2}{*}{$1 \mathrm{M} \mathrm{HCl}$} & 93.1 & \multirow[b]{2}{*}{2021} & \multirow[b]{2}{*}{ Our work } \\
\hline $\begin{array}{l}\text { 5'-(4-Amidino-3-fluorophenyl)-[2,2'-bithiophene]-5-carboxamidine dihydrochloride } \\
\text { salt (MA-1740) }\end{array}$ & & & 94.6 & & \\
\hline
\end{tabular}

Table 1. Corrosion inhibition efficiencies by EIS of previously studied bichalcophene derivatives in literature.

previously investigated in literature for C-steel alloys. The maximum \%IE results EIS corrosion measurements are summarized in Table 1. In the present investigation, we continue our work on studying new terthiophene and bithiophenes derivatives owing to its non-toxicity profile meriting corrosion efficiency of these compounds reported in our previous work. Terthiophene inhibitors are naturally occurring compounds ${ }^{15-17}$. The readability and accessibility of certain compounds that occur naturally in our local environment is a major advantage in harnessing their potentials as potential eco-friendly corrosion inhibitors. We aim in this study to advance our work by introducing two novel compounds and bench their corrosion inhibition potency against other bichalcophene compounds that previously reported in literature. This study encompasses synthesis work, experimental studies, surface analysis.

\section{Materials and methods}

The structure and molecular formula of studied cationic aryl bithiophene/terthiophene derivatives MA-1615, and MA-1740 are given in Table 2. The full details on the synthesis process and characterization (For ${ }^{1} \mathrm{H}-\mathrm{NMR}$, ${ }^{19} \mathrm{~F}-\mathrm{NMR}$, and Mass spectra of inhibitors see the Electronic Supplementary Material) are in the following part. The investigated inhibitors contain the same counter ion $\mathrm{Cl}^{-}$, so we assume that this counter ion has little effect in the prevailing acid environment of $1.0 \mathrm{M} \mathrm{HCl}$ compared to the cationic part.

Methodology for preparation of inhibitors. Monocationic terthiophene derivative 4. 4-(5'-Bromo[2,2'-bithiophen]-5-yl)-2-fluorobenzonitrile (2). Bromobithiophene derivative 2 was prepared starting from 4-([2,2'-bithiophen]-5-yl)-2-fluorobenzonitrile $(\mathbf{1})^{21}$, on treatment with NBS in DMF adopting the reported methodology ${ }^{21}$. Bromobithiophene compound 2 was obtained as a yellow solid in $87 \%$ yield, m.p. $170-171^{\circ} \mathrm{C}$ $(\mathrm{EtOH}) . \mathrm{R}_{\mathrm{f}}=0.72$, petroleum ether-EtOAc (8:2). IR $(\mathrm{KBr}) v / \mathrm{cm}^{-1} ; 3088(\mathrm{CH}$, stretch), $2230(\mathrm{CN}$, stretch), 1615, 1555, $1520\left(\mathrm{C}=\mathrm{C}\right.$, stretch). ${ }^{1} \mathrm{H}-\mathrm{NMR}$ (DMSO- $\left.d_{6}\right) ; \delta 7.24-7.27(\mathrm{~m}, 2 \mathrm{H}), 7.42(\mathrm{~d}, \mathrm{~J}=4.0 \mathrm{~Hz}, 1 \mathrm{H}$, thiophene-H), $7.66(\mathrm{~d}, \mathrm{~J}=8.4 \mathrm{~Hz}, 1 \mathrm{H}), 7.81(\mathrm{~d}, \mathrm{~J}=4.0 \mathrm{~Hz}, 1 \mathrm{H}$, thiophene-H), 7.87-7.94 ppm (m, 2H). MS (EI) m/e (rel.int.); 363, $365\left(\mathrm{M}^{+}, 94,100\right.$ : bromine isotopes). Anal. Calcd. for: $\mathrm{C}_{15} \mathrm{H}_{7} \mathrm{BrFNS}_{2}$ (364.25): C, 49.46; H, 1.94; N, 3.85 Found: C, $49.23 ; \mathrm{H}, 2.05 ; \mathrm{N}, 3.77 \%$.

4-([2,2':5',2'-Terthiophen]-5-yl)-2-fluorobenzonitrile (3). Terthienyl compound 3 was prepared adopting a Stille coupling conditions between 4-(5'-bromo-[2,2'-bithiophen]-5-yl)-2-fluorobenzonitrile (2), and 2-tributyltin thiophene adopting the reported methodology ${ }^{21}$. Compound 3 was obtained as an orange solid in $54 \%$ yield, m.p. $211-212^{\circ} \mathrm{C}(\mathrm{DMF} / \mathrm{EtOH}) . \mathrm{R}_{\mathrm{f}}=0.63$, petroleum ether-EtOAc (8:2). IR (KBr) v/cm ${ }^{-1} ; 3067(\mathrm{CH}$, stretch), 2228 (CN, stretch), 1612, 1556, 1513 (C=C, stretch). ${ }^{1} \mathrm{H}-\mathrm{NMR}\left(\mathrm{DMSO}-d_{6}\right) ; \delta 7.10-7.12(\mathrm{~m}, 1 \mathrm{H}) 7.32(\mathrm{~d}$, $\mathrm{J}=4.0 \mathrm{~Hz}, 1 \mathrm{H}$, thiophene-H), $7.37(\mathrm{~m}, 1 \mathrm{H}), 7.39(\mathrm{~d}, \mathrm{~J}=4.0 \mathrm{~Hz}, 1 \mathrm{H}$, thiophene-H), $7.46(\mathrm{~d}, \mathrm{~J}=4.0 \mathrm{~Hz}, 1 \mathrm{H}$, thiophene-H), 7.55-7.57 (m, 1H), 7.67 (dd, J = 8.0, 1.5 Hz, 1H), $7.83(\mathrm{~d}, \mathrm{~J}=4.0 \mathrm{~Hz}, 1 \mathrm{H}$, thiophene-H), 7.88-7.95 ppm (m, 2H). MS (EI) m/e (rel.int.); $367\left(\mathrm{M}^{+}, 100\right)$. Anal. Calcd. for $\mathrm{C}_{19} \mathrm{H}_{10} \mathrm{FNS}_{3}$ (367.48): C, 62.10; H, 2.74; N, 3.81 Found: C, 61.93; H, 2.92; N, 3.76\%.

4-([2,2':5',2'-Terthiophen]-5-yl)-2-fluorobenzamidine hydrochloride salt (4). Terthienylbenzamidine compound 4 was prepared by treatment of terthienyl-fluorobenzonitrile compound 3 with lithium bis-trimethylsilylamide adopting reported methodology ${ }^{21}$. Compound 4 was obtained as a reddish-brown solid in $63 \%$ yield, m.p. $292-293^{\circ} \mathrm{C}$. IR (KBr) v/ $\mathrm{cm}^{-1}$; 3389 (NH, stretch), $3063(\mathrm{CH}$, stretch), 1655, 1618, 1525 (C=N, C=C, stretch, $\mathrm{NH}$, bending). ${ }^{1} \mathrm{H}-\mathrm{NMR}\left(\mathrm{DMSO}-d_{6}\right) ; \delta 7.09-7.12(\mathrm{~m}, 1 \mathrm{H}), 7.30-7.46(\mathrm{~m}, 4 \mathrm{H}), 7.56(\mathrm{~d}, \mathrm{~J}=4.5 \mathrm{~Hz}, 1 \mathrm{H}$, thiophene$\mathrm{H})$, 7.64-7.72 (m, 2H), 7.80-7.86 (m, 2H), 9.38 (s, 2H, NH${ }_{2} ; \mathrm{D}_{2} \mathrm{O}$ exchangeable), 9.49 ppm (s, 2H, ${ }^{+} \mathrm{NH}_{2} ; \mathrm{D}_{2} \mathrm{O}$ exchangeable). ${ }^{19} \mathrm{~F}-\mathrm{NMR}$ (DMSO- $\left.d_{6}\right) ;-\delta 112.88 \mathrm{ppm}$ (using TFA as external standard). MS (EI) m/e (rel.int.); $384\left(\mathrm{M}^{+}, 99\right), 385\left(\mathrm{M}^{+}+1,100\right), 367\left(\mathrm{M}^{+}-\mathrm{NH}_{3}, 72\right)$. Anal. Calcd. for $\mathrm{C}_{19} \mathrm{H}_{13} \mathrm{FN}_{2} \mathrm{~S}_{3}-1.0 \mathrm{HCl}$ (420.97): C, 54.21; $\mathrm{H}$, $3.35 ; \mathrm{N}, 6.65$ Found: C, 54.37; H, 3.42; N, 6.53\%. 


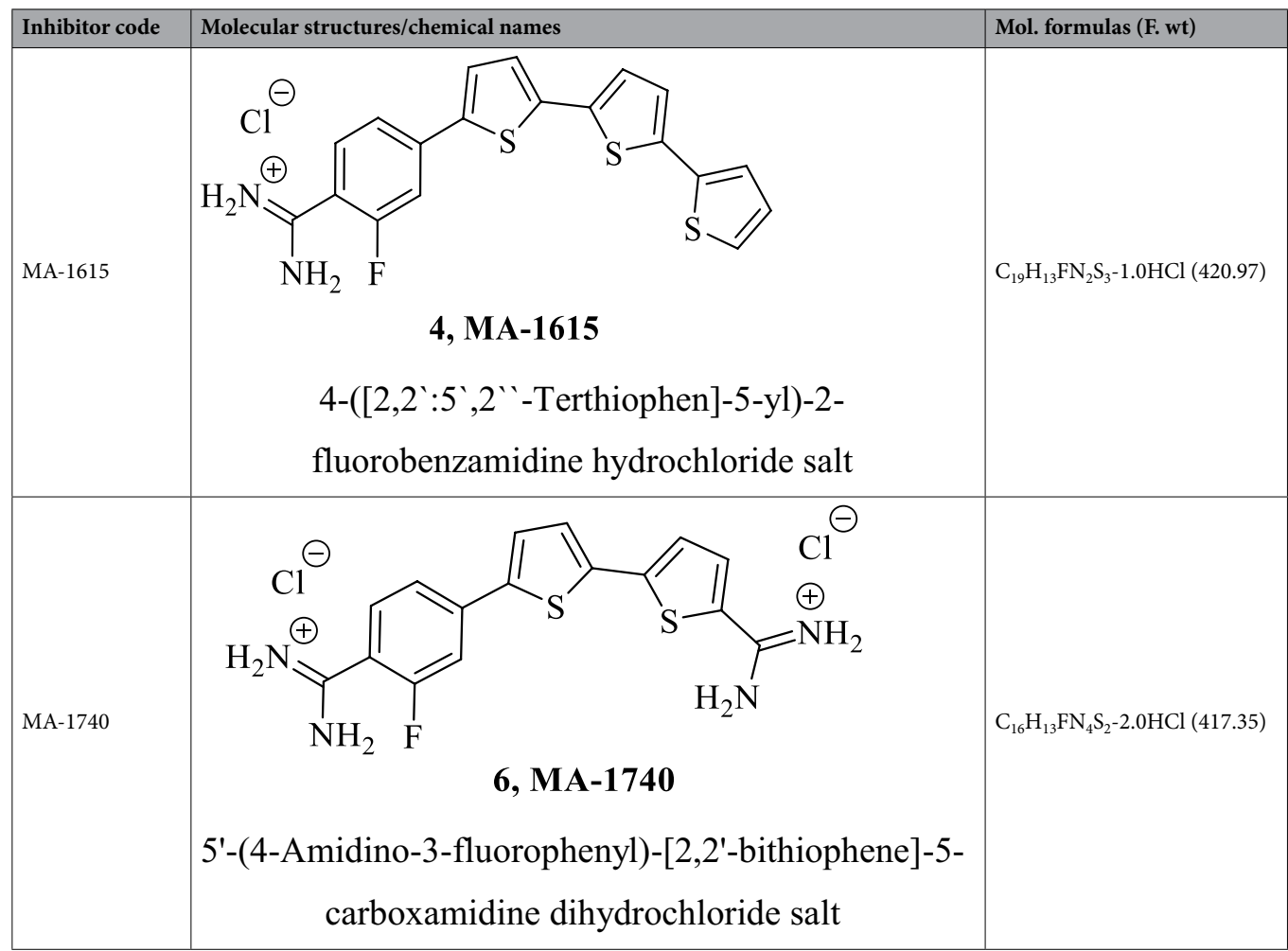

Table 2. Molecular structures, formulas, weights of bithiophene derivatives.

Dicationic bithiophene-5-carboxamidine derivative 6. 5'-(4-Cyano-3-fluorophenyl)-[2,2'-bithiophene]-5-carbo nitrile (5). A mixture of 4-(5'-bromo-[2,2'-bithiophen]-5-yl)-2-fluorobenzonitrile (2) (910 $\mathrm{mg}, 2.50 \mathrm{mmol})$ and $\mathrm{Cu}(\mathrm{I}) \mathrm{CN}(270 \mathrm{mg}, 3 \mathrm{mmol})$ in dry DMF $(25 \mathrm{~mL})$ was refluxed at $120-130^{\circ} \mathrm{C}$ for $48 \mathrm{~h}$. The reaction mixture was poured onto water/ammonia and extracted with ethyl acetate. The extract was washed with water and brine, dried over $\mathrm{Na}_{2} \mathrm{SO}_{4}$, then recrystallized from ethanol/EtOAc to afford the dicarbonitrile compound $\mathbf{5}$ as a yellow solid in $52 \%$ yield, m.p. $221-222.5^{\circ} \mathrm{C} . \mathrm{R}_{\mathrm{f}}=0.62$, petroleum ether-EtOAc $(8: 2)$. IR $(\mathrm{KBr}) \mathrm{v} / \mathrm{cm}^{-1} ; 3090(\mathrm{CH}$, stretch), 2212 (2CN, stretch), 1614, 1551, 1489 (C=C, stretch). ${ }^{1} \mathrm{H}-\mathrm{NMR}$ (DMSO- $d_{6}$ ); $\delta 7.57$ (d, J = 4.0 Hz, $1 \mathrm{H}$, thiophene-H), $7.67(\mathrm{~d}, \mathrm{~J}=4.0 \mathrm{~Hz}, 1 \mathrm{H}$, thiophene-H), $7.71(\mathrm{dd}, \mathrm{J}=8.5,2.0 \mathrm{~Hz}, 1 \mathrm{H}, \mathrm{Ar}-\mathrm{H}$ of fluorobenzonitrile ring), $7.89(\mathrm{~d}, \mathrm{~J}=4.0 \mathrm{~Hz}, 1 \mathrm{H}$, thiophene-H), 7.93-7.96 (m, 2H, Ar-H of fluorobenzonitrile ring), $7.98 \mathrm{ppm}(\mathrm{d}$, $\mathrm{J}=4.0 \mathrm{~Hz}, 1 \mathrm{H}$, thiophene-H). MS (EI) m/e (rel.int.); $310\left(\mathrm{M}^{+}, 100\right)$. Anal. Calcd. for: $\mathrm{C}_{16} \mathrm{H}_{7} \mathrm{FN}_{2} \mathrm{~S}_{2}$ (310.37): C, 61.92; H, 2.27; N, 9.03 Found: C, 62.05; H, 2.38; N, 8.83\%.

5'-(4-Amidino-3-fluorophenyl)-[2,2'-bithiophene]-5-carboxamidine dihydrochloride salt (6). Bithiophene diamidine compound $\mathbf{6}$ was prepared adopting the same conditions used for preparation of carboxamidine compound 4. Compound 6 was obtained in $69 \%$ yield as a yellowish-brown solid, m.p. $292-294{ }^{\circ} \mathrm{C}$. IR (KBr) v/ $\mathrm{cm}^{-1}$; 3342, $3187\left(\mathrm{NH}\right.$, stretch), $3087\left(\mathrm{CH}\right.$, stretch), 1663, 1619, $1523\left(\mathrm{C}=\mathrm{N}, \mathrm{C}=\mathrm{C}\right.$ stretch \& NH bending). ${ }^{1} \mathrm{H}-$ NMR (DMSO- $\left.d_{6}\right) ; \delta 7.65(\mathrm{~d}, \mathrm{~J}=4.0 \mathrm{~Hz}, 1 \mathrm{H}$, thiophene-H), $7.66(\mathrm{~d}, \mathrm{~J}=4.0 \mathrm{~Hz}, 1 \mathrm{H}$, thiophene-H), $7.73-7.75(\mathrm{~m}$, $2 \mathrm{H}, \mathrm{Ar}-\mathrm{H}$ of fluorobenzamidine ring), $7.89(\mathrm{~d}, \mathrm{~J}=4.0 \mathrm{~Hz}, 1 \mathrm{H}$, thiophene- $\mathrm{H}), 8.13(\mathrm{~d}, \mathrm{~J}=4.0 \mathrm{~Hz}, 1 \mathrm{H}$, thiophene$\mathrm{H}), 7.91\left(\mathrm{~d}, \mathrm{~J}=8.5 \mathrm{~Hz}, 1 \mathrm{H}, \mathrm{Ar}-\mathrm{H}\right.$ of fluorobenzamidine ring), $9.22\left(\mathrm{~s}, 2 \mathrm{H}, \mathrm{NH}_{2} ; \mathrm{D}_{2} \mathrm{O}\right.$ exchangeable), 9.45 (s, $2 \mathrm{H}$, $\mathrm{NH}_{2} ; \mathrm{D}_{2} \mathrm{O}$ exchangeable), $9.51\left(\mathrm{~s}, 2 \mathrm{H},{ }^{+} \mathrm{NH}_{2} ; \mathrm{D}_{2} \mathrm{O}\right.$ exchangeable), $9.54 \mathrm{ppm}\left(\mathrm{s}, 2 \mathrm{H},{ }^{+} \mathrm{NH}_{2} ; \mathrm{D}_{2} \mathrm{O}\right.$ exchangeable). ${ }^{19} \mathrm{~F}-\mathrm{NMR}$ (DMSO- $d_{6}$ ); $-\delta 112.76 \mathrm{ppm}$ (using TFA as external standard). MS (EI) m/e (rel.int.); $344\left(\mathrm{M}^{+}, 56\right), 327$ $\left(\mathrm{M}^{+}-\mathrm{NH}_{3}, 100\right), 310\left(\mathrm{M}^{+}-2 \mathrm{NH}_{3}, 49\right)$. Anal. Calcd. for $\mathrm{C}_{16} \mathrm{H}_{13} \mathrm{FN}_{4} \mathrm{~S}_{2}-2.0 \mathrm{HCl}$ (417.35): C, 46.05; H, 3.62; N, 13.42 Found: C, 45.78; H, 3.78; N, 13.17\%.

Corrosion measurements. Electrochemical measurements. Corrosion tests were conducted on API 5L X70 grade C-steel specimen with the following elemental structure (wt. \%): C, 0.026; Mn, 1.51; Si, 0.10; S, 0.02; $\mathrm{N}, 0.27 ; \mathrm{Ni}, 0.16 ; \mathrm{Al}, 0.35 ; \mathrm{Cr}, 0.27 ; \mathrm{Cu}, 0.28 ; \mathrm{Nb}, 0.93 ; \mathrm{Ti}, 0.11$; and remainder Fe. The corrosive electrolyte of $1 \mathrm{M} \mathrm{HCl}$ was freshly prepared by dilution of analytical grade $\mathrm{HCl}$ with a concentration of $37 \%$ using bi-distilled water. The concentration of MA-1615 and MA-1740 inhibitors in corrosive solution ranged from $1\left(1 \times 10^{6} \mathrm{M}\right)$ to $500 \mu \mathrm{M}\left(5 \times 10^{4} \mathrm{M}\right)$. Volta lab 80 (Tacussel-Radiometer PGZ-402) was used for electrochemical tests $\{$ Potentiodynamic polarization measurements (PP) and Electrochemical impedance spectroscopy (EIS)\}. Electrochemical tests were executed by the typical $250 \mathrm{ml}$ sealed electrochemical glass cell containing a finely cut API 5L X70 grade C-steel as working specimen, with an exposed surface area for $1 \mathrm{~cm}^{222}$. Platinum metallic sheet was mounted as the auxiliary electrode, and saturated calomel electrode (SCE) was utilized as the reference elec- 
trode. The surface of the working electrode was polished to mirror finish with various grades of emery papers (from 320 to 2000), degreased by acetone, cleaned by demineralized water and finally dried at room temperature before starting the tests. The reference electrode was placed close to the working electrode surface using LugginHaper capillary to nullify the iR potential drop between both the electrodes ends. EIS measurements were conducted via AC signal $(10 \mathrm{mV})$ peak to peak, in potentiostatic mode at open-circuit steady state potentials, in the frequency extent between $100 \mathrm{kHz}$ and $20 \mathrm{mHz}^{23}$. Potentiodynamic polarization (PP) tests were executed using the scan rate at $1 \mathrm{mV} \mathrm{s}^{-1}$ and sweeping the electrode potential $\pm 300 \mathrm{mV}$ relative to the steady state potential ${ }^{24}$. To ensure the consistency and accuracy of the results, all tests had been repeated three times.

Weight loss measurements. Tests were performed on petroleum pipeline alloy API 5L X70 carbon steel with density, $\mathrm{D}=7.86 \mathrm{~g} \mathrm{~cm}^{-3}$ and with the same chemical composition of the electrode material. The carbon steel coupons were fabricated with dimension $3 \times 2 \times 0.2 \mathrm{~cm}$. The surface of tested coupons was abraded using various grades of emery papers (from 320 to 2000), degreased with acetone, cleaned by demineralized water and finally dried at room temperature before starting the weight loss experiments. After weighing accurately, the specimens were immersed in $250 \mathrm{ml}$ beaker, which contained $150 \mathrm{ml}$ aggressive solution with and without addition of different concentrations of the tested inhibitors. After the required immersion time ( $48 \mathrm{~h})$, the test specimens were removed, washed with double distilled water, dried by a jet of air and finally weighed. The surface coverage area $(\theta)$ for the different concentrations of the investigated inhibitors in $1 \mathrm{M} \mathrm{HCl}$ "aggressive solution" and the inhibition efficiency from weight loss, $\eta_{\mathrm{w}}(\%)$ were calculated by the following Eq. (1):

$$
\eta_{w}(\%)=\theta \times 100=\left(\frac{\Delta W-\Delta W_{i}}{\Delta W}\right) \times 100,
$$

where, $\Delta \mathrm{W}$ and $\Delta \mathrm{W}_{\mathrm{i}}$ are the weight loss per unit area in absence and presence of additive, respectively. The rate of corrosion $(\mathrm{K})$ in $\left(\mathrm{mg} \mathrm{cm}^{-2} \mathrm{~h}^{-1}\right)$ was calculated by the following Eq. (2):

$$
K=\frac{\Delta W}{S t}
$$

where, $\Delta \mathrm{W}$ is the average weight loss of three parallel carbon steel sheets in $\mathrm{mg}, \mathrm{S}$ is the total area of the specimen in $\mathrm{cm}^{2}$ and $\mathrm{t}$ is the immersion time in hour.

UV-visible spectra measurement. UV-visible absorption spectrometric method was carried out for $(500 \mu \mathrm{M})$ of inhibitor solution, and the corrosive solution containing $(500 \mu \mathrm{M})$ of investigated inhibitor after immersion of $\mathrm{C}$-steel sample at $30^{\circ} \mathrm{C}$ for $28 \mathrm{~h}$. The spectra were measured using a PG instruments T80+ spectrometer.

Morphology analysis. Morphological investigation was carried out by Nanosurf Flex AFM for API X70 type C-steel samples, with dimensions $10 \times 10 \times 2 \mathrm{~mm}$. The API 5L X70 steel surface was pretreated in the identical way of the working electrode and immersed for $24 \mathrm{~h}$ in $1 \mathrm{M} \mathrm{HCl}$ solution without and with $0.001 \mathrm{M}$ of MA-1740 at $298 \pm 1 \mathrm{~K}$. Samples were collected, and then dried for analysis with $\mathrm{AFM}^{25}$.

\section{Results and discussion}

Synthesis and structure elucidation of inhibitors. Monocationic terthiophene derivative 4. The preparation of the new terthienylbenzamidine derivative 4 (Fig. 1) begins with bromination reaction of bithiophene derivative $\mathbf{1}^{21}$ with NBS to afford bromo bithiophene compounds $\mathbf{2}$ followed by a Stille coupling reaction with 2-tributyltin thiophene to furnish the terthienylbenzonitrile $\mathbf{3}$. Benzonitrile derivative $\mathbf{3}$ was allowed to react with lithium bis-trimethylsilylamide, followed by hydrolysis with hydrogen chloride. The resultant precipitate was neutralized with $1 \mathrm{~N} \mathrm{NaOH}$ to furnish the corresponding free base of terthienylbenzamidine 4 . The terthienylbenzamidine hydrochloride salt $\mathbf{4}$ was prepared by treatment of the proper free base of monoamidine with hydrogen chloride in ethanol.

Structure of the newly synthesized terthienylbenzonitrile derivative 3 was assigned based on its elemental and spectral analyses. IR spectra of the terthienylbenzonitrile 3 indicated the presence of nitrile group with stretching vibrations at $2228 \mathrm{~cm}^{-1}$. ${ }^{1} \mathrm{H}-\mathrm{NMR}$ spectrum of the fluorobenzonitrile derivative 3 displayed seven signal integrated for seven protons of terthienyl moiety and two signals integrated for three protons of 1,3,4-trisubstituted benzene ring. Mass spectrum of compound 3 gave a molecular ion peak m/z at $367\left(\mathrm{M}^{+}\right)$as a base peak. Structure of the newly synthesized terthienybenzamidine derivative 4 was assigned based on its elemental and spectral analyses. IR spectra of compound 4 indicated the disappearance of nitrile group and displayed new peaks corresponding for N-H stretching vibrations at $v^{\prime} 3460,3389 \mathrm{~cm}^{-1} .{ }^{1} \mathrm{H}-\mathrm{NMR}$ spectrum of the monocationic compound 4 gave two singlet signals at $\delta 9.38\left(2 \mathrm{H}, \mathrm{NH}_{2}\right)$ and $9.49\left(2 \mathrm{H},{ }^{+} \mathrm{NH}_{2}\right)$ of the cationic amidine group, plus five signals integrated for ten protons of terthienyl moiety and 1,3,4-trisubstituted benzene ring. ${ }^{19} \mathrm{~F}$-NMR displayed a singlet signal at $-\delta 112.88 \mathrm{ppm}$ (using TFA as external standard) of fluorine atom. Mass spectrum of terthienyl fluorobenzamidine derivative 4 gave a m/z peak at 384 of its molecular ion peaks $\left(\mathrm{M}^{+}\right)$, and $\mathrm{m} / \mathrm{z}$ peak at $385\left(\mathrm{M}^{+}+1\right)$ as a base peak, along with a fragment with $\mathrm{m} / \mathrm{z}$ peak at 367 due to loss of a molecule of ammonia.

Dicationic bithiophene-5-carboxamidine derivative 6. The preparation of the new bithiophene diamidine 6 (Fig. 2) begins with cyanation of 4-(5'-bromo-[2,2'-bithiophen]-5-yl)-2-fluorobenzonitrile (2) with $\mathrm{Cu}(1) \mathrm{CN}$ in DMF at $120-130^{\circ} \mathrm{C}$ to afford the dicarbonitrile derivative 5 . Dicarbonitrile derivative 5 was allowed to react with $\mathrm{LiN}(\mathrm{TMS})_{2}$, followed by hydrolysis with hydrogen chloride. The resultant precipitate was neutralized with $1 \mathrm{~N}$ 
<smiles>N#Cc1ccc(-c2ccc(-c3ccc(Br)s3)s2)cc1F</smiles>

(i)<smiles>N#Cc1ccc(-c2ccc(-c3cccs3)s2)cc1F</smiles>

(ii)<smiles>N#Cc1ccc(-c2ccc(-c3ccc(-c4cccs4)s3)s2)cc1F</smiles>

(iii)<smiles>N=C(N)c1ccc(-c2ccc(-c3ccc(-c4cccs4)s3)s2)cc1F</smiles>

Reagents and conditions: (i) NBS; (ii) 2-tributyltin thiophene, $\mathrm{Pd}\left(\mathrm{PPh}_{3}\right)_{4}$; (iii). a) $\mathrm{LiN}(\mathrm{TMS})_{2}$, b) ethanol/ $\mathrm{HCl}$ (gas)

Figure 1. Synthesis scheme for the new a-terthienylbenzamidine derivative 4 .<smiles>N#Cc1ccc(-c2ccc(-c3ccc(Br)s3)s2)cc1F</smiles>

(i)<smiles>N#Cc1ccc(-c2ccc(-c3ccc(C#N)c(F)c3)s2)s1</smiles>

(ii)<smiles>N=C(Cl)c1ccc(-c2ccc(-c3ccc(C(=N)N)c(F)c3)s2)s1</smiles>

Reagents and conditions: (i) $\mathrm{Cu}(\mathrm{I}) \mathrm{CN}$, anhydrous DMF; (ii). a) $\mathrm{LiN}(\mathrm{TMS})_{2}$, b) ethanol/HCl(gas)

Figure 2. Synthesis scheme for dicationic bithiophene-5-carboxamidine derivative 6.

$\mathrm{NaOH}$ to furnish the corresponding free base of diamidine $\mathbf{6}$. The diamidine hydrochloride salt $\mathbf{6}$ was prepared by treatment of its free base of diamidine with hydrogen chloride in ethanol.

Structure of the newly synthesized bithiophene dicarbonitrile derivative $\mathbf{5}$ was assigned based on its elemental and spectral analyses. IR spectra of the bithiophene dinitrile 5 indicated the presence of nitrile group with stretching vibrations at $2212 \mathrm{~cm}^{-1} .{ }^{1} \mathrm{H}-\mathrm{NMR}$ spectrum of compound 5 displayed four doublet signals (one proton each) of bithiophene moiety at $\delta 7.57,7.67,7.89,7.98 \mathrm{ppm}$, plus two signals integrated for three protons of 1,3,4-trisubstituted benzene moiety. Mass spectrum of compound 5 gave a molecular ion peak $\mathrm{m} / \mathrm{z}$ at $310\left(\mathrm{M}^{+}\right)$ as a base peak. The newly synthesized bithienylbenzamidine derivative $\mathbf{6}$ was assigned based on its elemental and spectral analyses. IR spectra of the diamidine $\mathbf{6}$ indicated the disappearance of the carbonitrile group and displayed new peaks corresponding for $\mathrm{N}-\mathrm{H}$ stretching vibrations at $v^{\prime} 3342,3187 \mathrm{~cm}^{-1}$. ${ }^{1} \mathrm{H}-\mathrm{NMR}$ spectrum of compound 6 gave four singlet signals at $\delta 9.22(2 \mathrm{H}), 9.45(2 \mathrm{H}), 9.51(2 \mathrm{H}), 9.54(2 \mathrm{H})$ characteristic for the cationic diamidine groups, four doublet signals at $\delta 7.65(1 \mathrm{H}), 7.66(1 \mathrm{H}), 7.89(1 \mathrm{H}), 8.13(1 \mathrm{H})$ of bithiophene$\mathrm{H}$ 's, plus two signals integrated for three protons of 1,3,4-trisubstituted benzene moiety. ${ }^{19} \mathrm{~F}$-NMR displayed a singlet signal at $-\delta 112.76 \mathrm{ppm}$ (using TFA as external standard) of fluorine atom. Mass spectrum of bithiophene 
<smiles>N=C(N)c1ccc(-c2ccc(-c3ccc(C(=N)N)c(F)c3)s2)s1</smiles>

$\mathrm{m} / \mathrm{z} 344\left(\mathrm{M}^{+}, 56\right)$

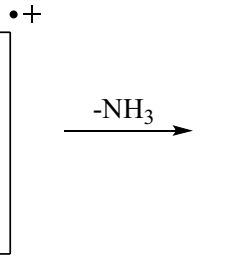<smiles>N#Cc1ccc(-c2ccc(-c3ccc(C(=N)N)s3)s2)cc1F</smiles>

$+$<smiles>N#Cc1ccc(-c2ccc(-c3ccc(C(=N)N)c(F)c3)s2)s1</smiles>

$\mathrm{m} / \mathrm{z} 327\left(\mathrm{M}^{+}-\mathrm{NH}_{3}, 100\right)$

Figure 3. Mass fragmentation pattern of bithienylbenzamidine derivative 6 .

diamidine compound 6 gave a m/z peak at 344 of its molecular ion peak $\left(\mathrm{M}^{+}\right)$, and $\mathrm{m} / \mathrm{z}$ peak at $327\left(\mathrm{M}^{+}-\mathrm{NH}_{3}\right)$ as a base peak, along with a fragment with $\mathrm{m} / \mathrm{z}$ peak at 310 due to loss of second molecule of ammonia (Fig. 3 ).

Weight loss measurements. Weight loss is a generally used technique for estimating the corrosion inhibition efficiency of inhibitors, and it has high reliability because the average corrosion rate can be determined over time. The corrosion behavior of API 5L X70 steel in $1 \mathrm{M} \mathrm{HCl}$ without and with different doses of MA-1740 and MA-1615 was studied by weight loss method. Figure 4 shows the corrosion rate $(\mathrm{k})$ and inhibition efficiency $\left(\mathrm{IE}_{\mathrm{w}} \%\right)$ of the inhibitors. As shown in Fig. 4, the corrosion rate values are obviously reduced, and inhibition efficiency was increased after adding various doses of inhibitors. The maximum $\mathrm{IE}_{\mathrm{w}} \%$ values of MA-1156 and MA-1740 are $93.57 \%$ and $94.16 \%$, respectively. The inhibition behavior of the cationic aryl bithiophene/terthiophene derivatives can be explained by the adsorption of their molecules on the surface of carbon steel. According to Hammet substituent coefficient, MA-1740 has one more substituent $-\mathrm{NH}_{2}$ group that has negative value of $\sigma$ $(-0.22)$ this indicates that capacity of MA-1740 to adsorb on metal surface is higher than MA-1615 as a result of increase in the electron density on the adsorption $\operatorname{sites}^{26}$.

Electrochemical results. Potentiodynamic polarization (PP) studies. Tafel plots of immersed API 5L X70 grade C-steel electrode in $1 \mathrm{M} \mathrm{HCl}$ without and with different doses of $\mathrm{MA}-1740$ at $25^{\circ} \mathrm{C}$ is represented in Fig. 5. Electrochemical variables obtained from extrapolation of Tafel curves were summarized in Table 3. It is obvious that with increasing the inhibitor concentration, the generated corrosion current density $\left(i_{\text {corr }}\right)$ for the API 5L X70 grade C-steel sample in the acidic medium shows a decreasing trend. This behaviour demonstrates the ability of the cationic aryl bithiophene/terthiophene derivatives to increase in the inhibition efficiencies and to reduce the corrosion rate caused via acidic solution. Looking at the PP plots showed that the anodic and cathodic lines, it is obvious that the curves tend to decline, which is an indication of the adsorption of cationic aryl bithiophene/terthiophene derivatives on the $\mathrm{C}$-steel surface lower cathodic hydrogen evolution and anodic dissolution of $\mathrm{Fe}$ ions. Additionally, the difference in the values of Tafel slopes $\left(\beta_{\mathrm{a}}\right.$ and $\left.\beta_{\mathrm{c}}\right)$ with different doses of cationic aryl bithiophene/terthiophene derivatives was small, indicating that the cationic aryl bithiophene/ terthiophene derivatives hindered the corrosion of API 5L X70 type C-steel via inhibiting both anodic and cathodic reactions, without changing the corrosion process mechanism ${ }^{27,28}$. Tafel polarization was carried out at different temperature for the dicationic bithiophene inhibitor MA-1740 at optimum concentration of study as in Fig. 6. The corrosion measurements by Tafel polarization at different temperature are summarized in Table 4. From the results, it is obvious that the current density is higher when increasing the temperature, and so does the desorption rate of compounds on metal surface. However, this has no big shift in plots as can be seen in Fig. 6, this indicates no change in adsorption mechanism of compounds. The adsorption of cationic aryl bithiophene/ terthiophene derivatives on API 5L X70 can be attributed to the interaction between the lone pairs of sulfur and nitrogen atoms present in these derivatives and the empty d-orbital of API 5L X70-type C-steel surface via coordination bonds. The resulting protection was achieved with the creation of a barrier film and led to inhibit corrosion. The inhibition efficiency $\left(\eta_{\mathrm{p}}\right)$ can be calculated by the following equation ${ }^{29,30}$ :

$$
\eta_{p}=\left[\frac{i_{\text {corr }}^{0}-i_{\text {corr }}}{i_{\text {corr }}^{0}}\right] \times 100
$$

where $i_{\text {corr }}^{0}$ and $i_{\text {corr }}$ are the corrosion current density without and with the studied inhibitors, respectively. From Table 3, the presence of two cationic aryl bithiophene derivative make the corrosion potential $\left(E_{\text {corr }}\right)$ to change to more positive and negative potentials compared with the blank solution. The $E_{\text {corr }}$ values were significantly less than $85 \mathrm{mV} / \mathrm{SCE}$, indicating that the studied cationic aryl bithiophene/terthiophene derivatives were mixed-type 

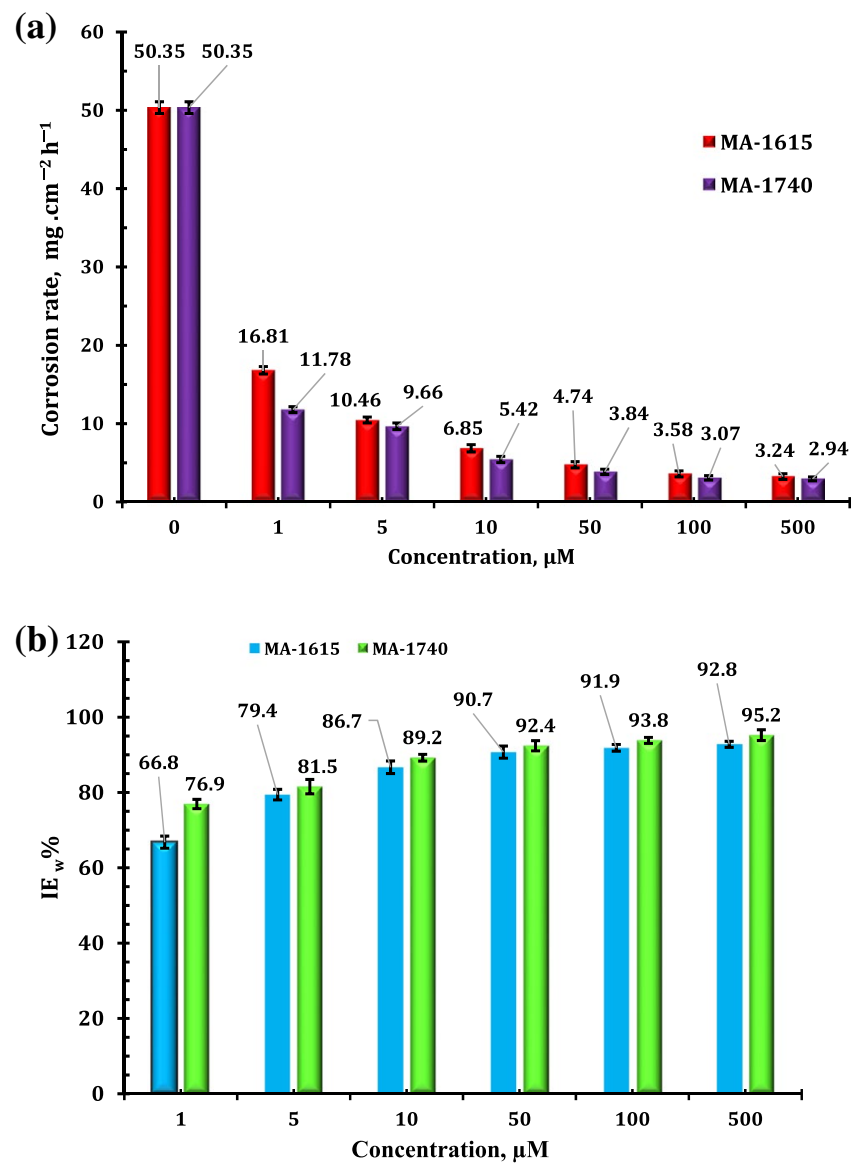

Figure 4. Variation of (a) corrosion rate and (b) inhibition efficiency with various doses of cationic aryl bithiophene/terthiophene additives by weight loss. Error bars ( $\mathrm{T}$ ) represent the standard deviations (\%).

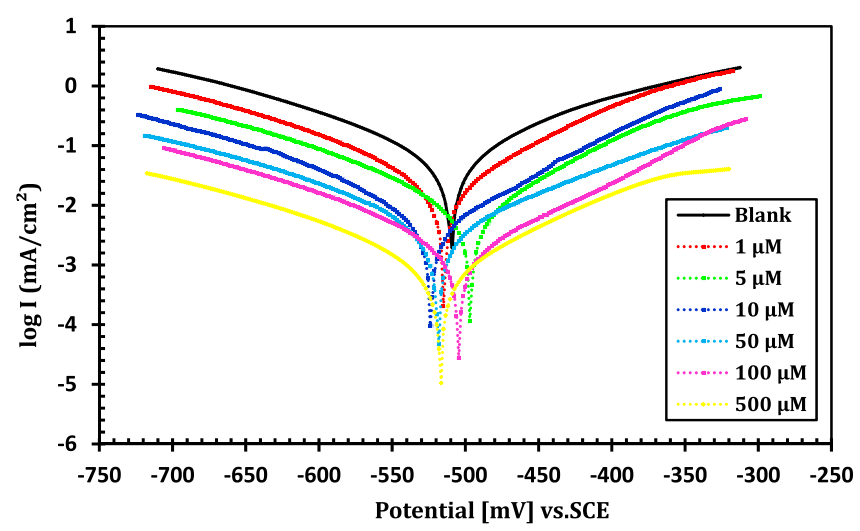

Figure 5. Potentiodynamic polarization curves of $\mathrm{C}$-steel in $1 \mathrm{M} \mathrm{HCl}$ with different concentrations of inhibitor MA- 1740 at $25^{\circ} \mathrm{C}$.

inhibitors $^{31-33}$. In addition, the inhibitory activity of cationic aryl bithiophene/terthiophene improved by the presence of lone pairs of electrons and thiophene moiety in these compounds, as well as number of cationic amidine groups. Interestingly, addition of second cationic amidine group improvement outweighs the addition of third thiophene group and this may be attributed to solubility effect of the cationic group. For that reason, cationic aryl bithiophene/terthiophene derivatives can be ordered according to their efficiency as anti-corrosion of API 5L X70-type C-steel in HCl solution as follows: MA-1740 > MA-1615.

Electrochemical impedance spectroscopy (EIS) test. EIS is a widely utilized tool in corrosion inhibition studies of metals $^{34}$. The corrosion behaviour of API 5L X70-type C-steel in $\mathrm{HCl}$ solution without and with different doses of the cationic aryl bithiophene/terthiophene derivatives was demonstrated by impedance tests. Figures 7 and 8 


\begin{tabular}{|c|c|c|c|c|c|c|c|}
\hline Inhibitor & $C(\mu \mathrm{M})$ & $-E_{\text {corr }}\left(\mathrm{mV}_{\mathrm{SCE}}\right)$ & $i_{\text {corr }}\left(\mathrm{mA} \mathrm{cm}^{-2}\right)$ & $\left.\beta_{\mathrm{a}}(\mathrm{mV} \mathrm{dec})^{-1}\right)$ & $\left.-\beta_{\mathrm{c}}(\mathrm{mV} \mathrm{dec})^{-1}\right)$ & $\theta$ & $\eta_{\mathrm{p}}(\%)$ \\
\hline Blank & - & $509.2 \pm 4$ & $0.6381 \pm 0.03$ & $107.2 \pm 1.4$ & $149.5 \pm 2.3$ & - & - \\
\hline \multirow{6}{*}{ MA-1615 } & 1 & $502.1 \pm 6$ & $0.1829 \pm 0.06$ & $85.3 \pm 1.6$ & $160.2 \pm 1.9$ & 0.7134 & 71.34 \\
\hline & 5 & $511.5 \pm 3$ & $0.1501 \pm 0.07$ & $119.4 \pm 1.9$ & $134.1 \pm 1.4$ & 0.7648 & 76.48 \\
\hline & 10 & $517.3 \pm 5$ & $0.1145 \pm 0.08$ & $98.3 \pm 2.1$ & $171.4 \pm 1.7$ & 0.8206 & 82.06 \\
\hline & 50 & $506.9 \pm 2$ & $0.0924 \pm 0.02$ & $126.1 \pm 1.3$ & $153.7 \pm 1.8$ & 0.8552 & 85.52 \\
\hline & 100 & $488.4 \pm 7$ & $0.0689 \pm 0.05$ & $87.9 \pm 2.1$ & $182.3 \pm 0.9$ & 0.8920 & 89.20 \\
\hline & 500 & $493.7 \pm 3$ & $0.0278 \pm 0.04$ & $93.2 \pm 1.6$ & $131.6 \pm 0.7$ & 0.9564 & 95.64 \\
\hline \multirow{6}{*}{ MA- 1740} & 1 & $514.9 \pm 5$ & $0.1578 \pm 0.08$ & $121.9 \pm 1.3$ & $138.2 \pm 0.6$ & 0.7527 & 75.27 \\
\hline & 5 & $497.1 \pm 4$ & $0.1402 \pm 0.05$ & $106.1 \pm 0.7$ & $169.4 \pm 2.4$ & 0.7803 & 78.03 \\
\hline & 10 & $524.2 \pm 2$ & $0.1036 \pm 0.06$ & $86.5 \pm 1.1$ & $218.1 \pm 1.9$ & 0.8376 & 83.76 \\
\hline & 50 & $518.3 \pm 6$ & $0.0798 \pm 0.07$ & $114.3 \pm 0.6$ & $171.5 \pm 0.8$ & 0.8749 & 87.49 \\
\hline & 100 & $504.7 \pm 3$ & $0.0554 \pm 0.03$ & $129.4 \pm 1.5$ & $164.9 \pm 1.6$ & 0.9132 & 91.32 \\
\hline & 500 & $516.4 \pm 8$ & $0.0197 \pm 0.02$ & $76.2 \pm 0.9$ & $172.6 \pm 0.7$ & 0.9691 & 96.91 \\
\hline
\end{tabular}

Table 3. Electrochemical kinetic parameters obtained from the polarization measurements on C-steel in uninhibited and inhibited acid solutions with different inhibitors doses at $25^{\circ} \mathrm{C}$.

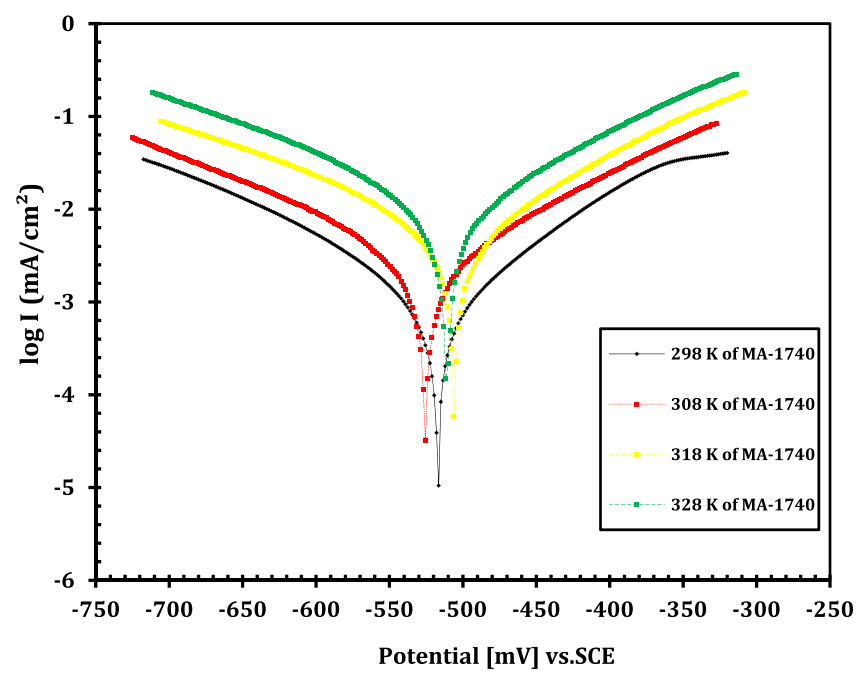

Figure 6. Effect of temperature on the Tafel polarization curves of C-steel in $1.0 \mathrm{M} \mathrm{HCl}$ with and without compounds.

\begin{tabular}{|c|c|c|c|c|c|c|c|}
\hline Inhibitor & $\mathrm{T}(\mathrm{K})$ & $-E_{\text {corr. }} \mathrm{mV}(\mathrm{vs} . \mathrm{SCE})$ & $I_{\text {corr. }}, \mathrm{mAcm}^{-2}$ & $\beta_{\mathrm{a}}, \mathrm{mVdec}^{-1}$ & $-\beta_{\mathrm{c}}, \mathrm{mVdec}^{-1}$ & $\theta$ & IE \% \\
\hline \multirow{4}{*}{ Blank } & 298 & $509.2 \pm 4$ & $0.6381 \pm 0.03$ & $107.2 \pm 1.4$ & $149.5 \pm 2.3$ & - & - \\
\hline & 308 & $504.6 \pm 3$ & $0.9613 \pm 0.06$ & $94.1 \pm 1.8$ & $153.7 \pm 1.8$ & - & - \\
\hline & 318 & $512.9 \pm 2$ & $1.2541 \pm 0.08$ & $91.6 \pm 1.5$ & $128.9 \pm 0.7$ & - & - \\
\hline & 328 & $517.5 \pm 6$ & $1.8562 \pm 0.02$ & $87.3 \pm 0.9$ & $146.1 \pm 2.1$ & - & - \\
\hline \multirow{4}{*}{ MA-1615 } & 298 & $493.7 \pm 3$ & $0.0278 \pm 0.04$ & $93.2 \pm 1.6$ & $131.6 \pm 0.7$ & 0.9564 & 95.64 \\
\hline & 308 & $489.1 \pm 5$ & $0.1135 \pm 0.05$ & $101.8 \pm 1.2$ & $183.4 \pm 1.5$ & 0.8819 & 88.19 \\
\hline & 318 & $497.3 \pm 2$ & $0.1943 \pm 0.03$ & $94.1 \pm 0.8$ & $176.9 \pm 1.2$ & 0.8451 & 84.51 \\
\hline & 328 & $508.9 \pm 4$ & $0.3849 \pm 0.07$ & $89.3 \pm 1.3$ & $165.1 \pm 0.9$ & 0.7926 & 79.26 \\
\hline \multirow{4}{*}{ MA-1740 } & 298 & $516.4 \pm 8$ & $0.0197 \pm 0.02$ & $76.2 \pm 0.9$ & $172.6 \pm 0.7$ & 0.9691 & 96.91 \\
\hline & 308 & $525.6 \pm 3$ & $0.0891 \pm 0.05$ & $104.1 \pm 0.6$ & $159.3 \pm 1.4$ & 0.9073 & 90.73 \\
\hline & 318 & $506.3 \pm 5$ & $0.1796 \pm 0.04$ & $96.2 \pm 1.3$ & $178.4 \pm 1.2$ & 0.8568 & 85.68 \\
\hline & 328 & $511.6 \pm 7$ & $0.3454 \pm 0.01$ & $103.4 \pm 1.7$ & $185.1 \pm 0.9$ & 0.8139 & 81.39 \\
\hline
\end{tabular}

Table 4. Electrochemical kinetic parameters obtained from the polarization measurements on C-steel in uninhibited and inhibited acid solutions with optimum inhibitors doses at different temperature. 


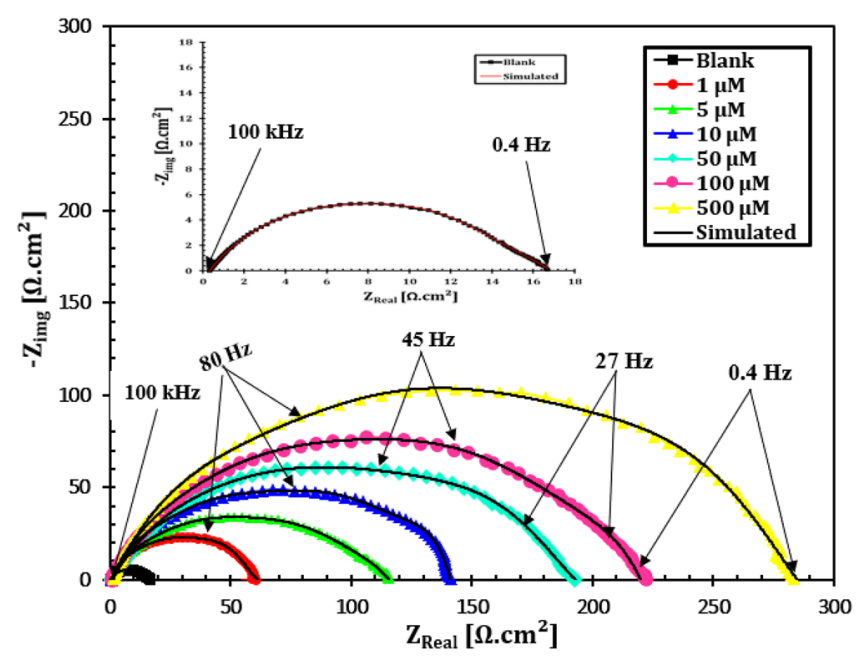

Figure 7. Nyquist plots of $\mathrm{C}$-steel in $1 \mathrm{M} \mathrm{HCl}$ with different concentrations of inhibitor MA-1740 at $25^{\circ} \mathrm{C}$.

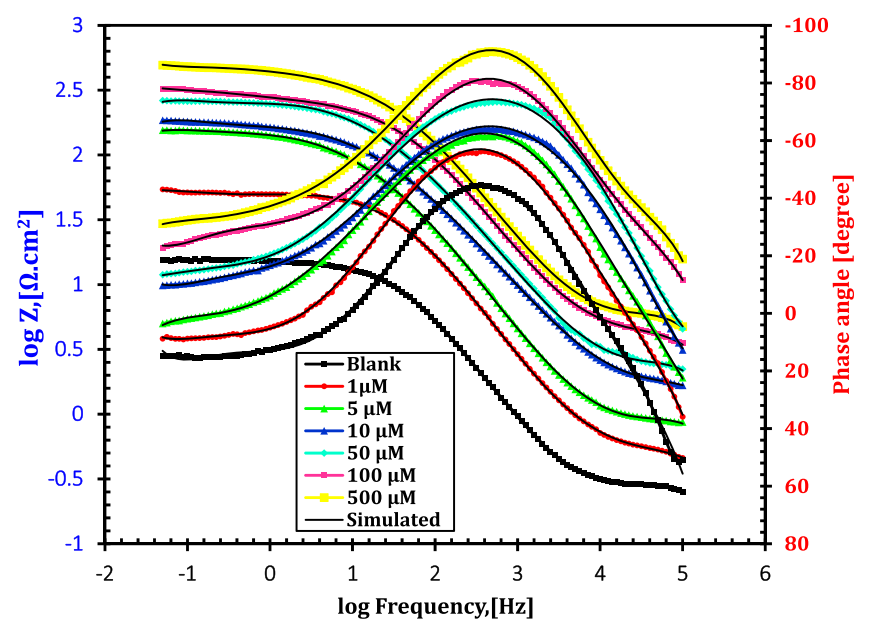

Figure 8. Bode plots of C-steel in $1 \mathrm{M} \mathrm{HCl}$ with different concentrations of inhibitor MA- 1740 at $25^{\circ} \mathrm{C}$.

show the Nyquist and Bode plots, respectively of immersed API 5L X70 grade C-steel electrode in $1 \mathrm{M} \mathrm{HCl} \mathrm{solu-}$ tion without and with different doses of dicationic compound MA- 1740 inhibitor at $25^{\circ} \mathrm{C}$. The electrochemical impedance parameters were summarized in Table 5. Nyquist plot in Fig. 7 displayed single capacitive loops, presenting that the dissolution process of API 5L X70 grade C-steel electrode in $1 \mathrm{M} \mathrm{HCl}$ solution in the absence and presence of inhibitors undergoes through charge-transfer and double-layer capacitance at the interface of C-steel/solution. As shown in Figs. 7 and 8, the Nyquist and Bode plots show the same style, inferring that the mechanism of cathodic and anodic corrosion reactions was not altered upon addition of cationic aryl bithiophene/terthiophene inhibitors. Whereas, the semicircles diameter becomes a little wider with raising the doses of studied cationic aryl bithiophene/terthiophene derivatives in $1 \mathrm{M} \mathrm{HCl}$ corrosive solution ${ }^{35,36}$. In addition, the Bode curves for the studied inhibitors in Fig. 8 exposed that the phase angle and the absolute impedance curves turned wider and larger with the rise in the inhibitor doses; such modifications support the inhibiting action of these inhibitor molecules against the corrosion of API 5L X70 type C-steel in $1 \mathrm{M} \mathrm{HCl}$ solution ${ }^{37}$.

The equivalent circuit for data fitting experiments was presented in Fig. 9, and the fitted EIS data were given in Table 5. The electrical equivalent circuit includes solution resistance $\left(R_{\mathrm{s}}\right)$, charge transfer resistance $\left(R_{\mathrm{ct}}\right)$, and the constant phase element $(C P E) . C_{\mathrm{dl}}$ is the double-layer capacitor. The $C P E$ impedance $\left(Z_{\mathrm{CPE}}\right)$ is calculated by the following equations ${ }^{38-40}$ :

$$
\begin{gathered}
Z_{C P E}=\frac{1}{Y_{0}(j \omega)^{n}}, \\
C_{d l}=Y_{0}\left(\omega_{\text {max }}\right)^{n-1},
\end{gathered}
$$




\begin{tabular}{|l|l|l|l|l|c|l|l|}
\hline Inhibitor & Conc. $(\boldsymbol{\mu M})$ & $\boldsymbol{R s}\left(\boldsymbol{\Omega} \mathbf{c m}^{2}\right)$ & $\mathbf{R}^{2}$ & $\boldsymbol{n}$ & $\boldsymbol{C}_{\mathrm{dl}}\left(\boldsymbol{\mu} \mathbf{F} / \mathbf{c m}^{2}\right)$ & $\boldsymbol{R}_{\mathrm{ct},}\left(\boldsymbol{\Omega} \mathbf{c m}^{2}\right)$ & $I E \%$ \\
\hline Blank & - & $1.391 \pm 0.02$ & 0.996 & $0.919 \pm 0.03$ & $107.23 \pm 0.8$ & $15.4 \pm 0.5$ & - \\
\hline \multirow{5}{*}{ MA-1615 } & 1 & $2.723 \pm 0.06$ & 0.986 & $0.992 \pm 0.04$ & $51.36 \pm 0.5$ & $50.3 \pm 1.3$ & 69.5 \\
\cline { 2 - 8 } & 5 & $1.182 \pm 0.12$ & 0.964 & $0.994 \pm 0.05$ & $47.51 \pm 1.2$ & $58.7 \pm 0.9$ & 73.8 \\
\cline { 2 - 8 } & 10 & $1.305 \pm 0.03$ & 0.971 & $0.963 \pm 0.02$ & $36.57 \pm 0.7$ & $79.1 \pm 0.6$ & 80.6 \\
\cline { 2 - 8 } & 50 & $1.578 \pm 0.12$ & 0.966 & $0.999 \pm 0.08$ & $27.19 \pm 0.9$ & $94.5 \pm 0.7$ & 83.7 \\
\cline { 2 - 8 } & 100 & $1.239 \pm 0.04$ & 0.985 & $0.973 \pm 0.01$ & $20.31 \pm 0.5$ & $126.8 \pm 1.4$ & 87.9 \\
\cline { 2 - 8 } & 500 & $1.687 \pm 0.05$ & 0.982 & $0.964 \pm 0.07$ & $9.05 \pm 0.3$ & $224.2 \pm 0.8$ & 93.1 \\
\hline \multirow{5}{*}{ MA-1740 } & 1 & $1.745 \pm 0.43$ & 0.993 & $0.959 \pm 0.02$ & $48.39 \pm 1.1$ & $57.3 \pm 0.2$ & 73.2 \\
\cline { 2 - 8 } & 5 & $1.953 \pm 0.06$ & 0.992 & $0.984 \pm 0.06$ & $42.16 \pm 1.4$ & $67.1 \pm 0.6$ & 77.1 \\
\cline { 2 - 8 } & 10 & $1.523 \pm 0.39$ & 0.979 & $0.995 \pm 0.05$ & $34.23 \pm 0.7$ & $82.4 \pm 0.7$ & 81.4 \\
\cline { 2 - 8 } & 50 & $1.314 \pm 0.17$ & 0.984 & $0.998 \pm 0.03$ & $23.15 \pm 0.9$ & $108.9 \pm 1.1$ & 85.9 \\
\cline { 2 - 8 } & 100 & $1.295 \pm 0.23$ & 0.997 & $0.995 \pm 0.04$ & $16.42 \pm 0.6$ & $143.5 \pm 0.9$ & 89.3 \\
\cline { 2 - 8 } & 500 & $1.791 \pm 0.04$ & 0.983 & $0.982 \pm 0.07$ & $5.24 \pm 0.2$ & $286.2 \pm 1.3$ & 94.6 \\
\hline
\end{tabular}

Table 5. Electrochemical parameters obtained from EIS equivalent circuit fitting of the C-steel immersed in $1 \mathrm{M} \mathrm{HCl}$ without and with various doses of inhibitor.

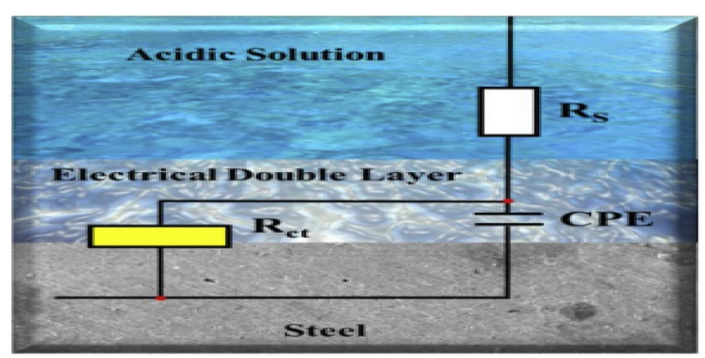

Figure 9. Equivalent circuit used to model metal/solution interface of C-steel in $1 \mathrm{M} \mathrm{HCl}$ without and with the cationic aryl bi-thiophene derivatives.

where $j$ is the imaginary root $\left(\mathrm{j}^{2}=-1\right), Y_{0}$ represents the modules of CPE, $\omega$ represents the angular frequency, $n$ represents the deviation index in terms of a phase shift, $2 \omega_{\max }=2 \pi f_{\max }$, and $f_{\max }$ represents the frequency at the maximum value of the imaginary component of EIS spectra. The values of $\eta_{E I S}$ from EIS parameters of the cationic aryl bi-thiophene derivatives inhibitors can be obtained by the following equations $\mathrm{s}^{41}$ :

$$
\eta_{i}=\left[\frac{R_{c t}-R_{c t}^{0}}{R_{c t}}\right] \times 100
$$

where $R_{c t}$ and $R_{c t}^{0}$ denotes the charge transfer resistances for C-steel in inhibited and uninhibited acid test solutions, respectively. The data in Table 5 revealed that $\mathrm{R}_{\mathrm{ct}}$ values is higher when the dose of cationic bithiophene/ terthiophene additives increases in test solutions. While we notice drop in the values of $\mathrm{C}_{\mathrm{dl}}$ with uplifting the concentration of inhibitors in acid medium. This action can be correlated to the adsorption of studied cationic bithiophene/terthiophene derivatives on C-steel/electrolyte interface that blocks corrosion reactions on C-steel surface and protect the metal from further acid attack ${ }^{42}$. The data in Table 5 revealed that the lower value of $\mathrm{n}$ in the blank solution (free from inhibitor molecules) can be attributed to the attack of aggressive ions on carbon steel surface leading to increase the heterogeneity of the surface. However, in the presence of inhibitor concentrations the values of $\mathrm{n}$ increase due to the formation of protection film and increasing the homogeneity of the surface ${ }^{41,43}$.

In view of the results presented in Table 5 , the adsorption of the cationic bithiophene/terthiophene derivatives molecules onto the surface of API 5L X70 type C-steel occurs by substituting the existing water molecules and then creating a thicker and more ordered fencing protection layer. This has resulted in their ability to inhibit electron transfer and generally mitigate the corrosion reaction ${ }^{44,45}$. The EIS results revealed that the value of $R_{c t}$ increases gradually with the increase in concentration of the synthesized inhibitors and this indicates an increase in the corrosion inhibition efficiency, which agrees with the potentiodynamic polarization results obtained.

Regression coefficients $\left(\mathrm{R}^{2}\right)$ is listed in Table 5.

$\mathrm{R}^{2}$ is a statistic that will give some information about the goodness of fit of a model. In regression, the $\mathrm{R}^{2}$ coefficient of determination is a statistical measure of how well the regression predictions approximate the real data points. An $\mathrm{R}^{2}$ of 1 indicates that the regression predictions perfectly fit the data. The data in Table 5 revealed that $\mathrm{R}^{2}$ is an approximation of 1 indicating that the regression predictions fit well with the EIS data. 


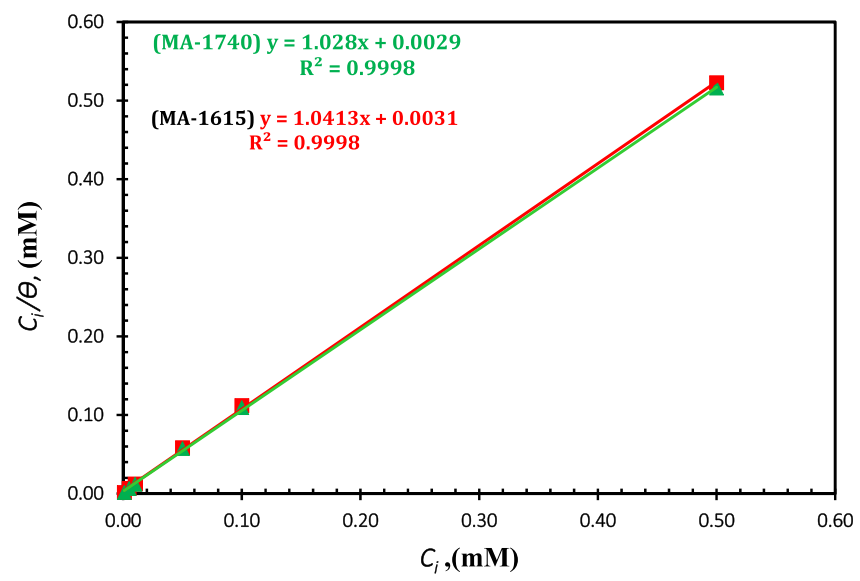

Figure 10. Langmuir adsorption plots for the cationic aryl bithiophene/terthiophene inhibitors on API 5L X70type C-steel in $1 \mathrm{M} \mathrm{HCl}$.

\begin{tabular}{|l|l|l|l|l|l|}
\hline Inhibitor & Slope & Regression coefficient $\left(\boldsymbol{R}^{2}\right)$ & intercept & $\mathbf{K}_{\text {ads }}\left(\mathbf{L} \mathbf{~ m o l}^{-1}\right)$ & $-\Delta \mathbf{G}_{\text {ads }}^{\circ}\left(\mathbf{k J ~ m o l}^{-1}\right)$ \\
\hline MA-1615 & 1.0413 & 0.9998 & 0.0031 & $322,580.65$ & 41.38 \\
\hline MA-1740 & 1.028 & 0.9998 & 0.0029 & $344,827.59$ & 41.54 \\
\hline
\end{tabular}

Table 6. Adsorption equilibrium constant $\left(K_{\mathrm{ads}}\right)$ and standard free energy of adsorption $\left(\Delta G_{\mathrm{ads}}^{\circ}\right)$ of the investigated inhibitors for $\mathrm{C}$-steel in $1 \mathrm{M} \mathrm{HCl}$ solution at $25^{\circ} \mathrm{C}$.

Adsorption study. The inhibition potential of corrosion inhibitor depends on the adsorption behaviour on $\mathrm{C}$-steel surface. To investigate the type adsorption reaction of the cationic aryl bithiophene/terthiophene derivatives on API 5L X70-type C-steel surface, the adsorption isotherms must be investigated. Langmuir adsorption isotherm showed the best fit for the tested cationic aryl bithiophene/terthiophene derivatives that is defined as follows ${ }^{46}$ :

$$
\frac{C}{\theta}=\frac{1}{K_{a d s}}+C
$$

where $K_{\text {ads }}$ is the adsorption equilibrium constant, $C$ represents the inhibitor concentration, and $\theta$ is the surface coverage. Figure 10 represents the plotted curves of $C / \theta$ versus $C$ for the investigated compounds, which gave a straight line, and the extracted parameters were recorded in Table 6. The linear correlation coefficient $\left(R^{2}\right)$ and slope of these linear curves were found close to unity, indicating that the adsorption of these cationic aryl bithiophene/terthiophene derivatives on the surface of API 5L X70 type C-steel in $1 \mathrm{M} \mathrm{HCl}$ solution follow the Langmuir isotherm. The Gibbs standard free energy $\left(\Delta G_{a d s}^{o}\right)$, which is a useful thermodynamic parameter in our study was calculated as follows ${ }^{18,47,48}$ :

$$
\Delta G_{a d s}^{o}=-R T \ln \left(55.5 K_{a d s}\right),
$$

where $R$ is the gas constant, $T$ represents the absolute temperature, and $K_{a d s}$ is the adsorption equilibrium constant that can be calculated from the interception of the isotherm line with the C/ $\theta$ axis. The values of $K_{\text {ads }}$ and $\Delta G_{a d s}^{o}$ were listed in Table 6 . The higher values of $K_{\text {ads }}$ indicate the strong adsorption ability of these studied cationic aryl bithiophene/terthiophene derivatives on the surface of API 5L X70 type C-steel in $1 \mathrm{M} \mathrm{HCl} \mathrm{solu-}$ tion, and then enhanced protection against corrosion. From the results in Table 6 , the values of $\Delta G_{a d s}^{o}$ are negative, which indicates that the adsorption of the studied inhibitors on C-steel surface is a spontaneous process. Inspecting the obtained values of $\Delta G_{a d s}^{o}$ in Table 6 , the $\Delta G_{\text {ads }}^{\circ}$ values of the studied inhibitors ranged from -33.88 to $-36.13 \mathrm{~kJ} \mathrm{~mol}^{-1}$, so it is the adsorption process occurs through both physical and chemical adsorption type of interactions ${ }^{49-51}$.

UV-visible spectrometric measurements. According to the literature reports, the influence of corrosion inhibition on metals in the test media in the presence of an inhibitor may be attributed to the complex formation between a metal and an inhibitor ${ }^{52-54}$. In our present work, in order to confirm the possibility of a complex formation between the C-steel electrode and the inhibitor molecules, UV-Vis spectrometric measurements were recorded for $(500 \mu \mathrm{M})$ of the inhibitor, $(500 \mu \mathrm{M}) \mathrm{HCl}$ solution containing $(500 \mu \mathrm{M})$ of inhibitor after C-steel immersion for $28 \mathrm{~h}$ at $30^{\circ} \mathrm{C}$ (Fig. 11a,b). The electronic spectra of investigated inhibitors (Fig. 11a,b) show visible peaks at (394, and $335 \mathrm{~nm})$, and (396, and $337 \mathrm{~nm}$ ) for MA-1615, and MA-1740, respectively. This may be attributed to the $\pi-\pi^{*}$ transition with an important charge transfer character. On the other hand, after 

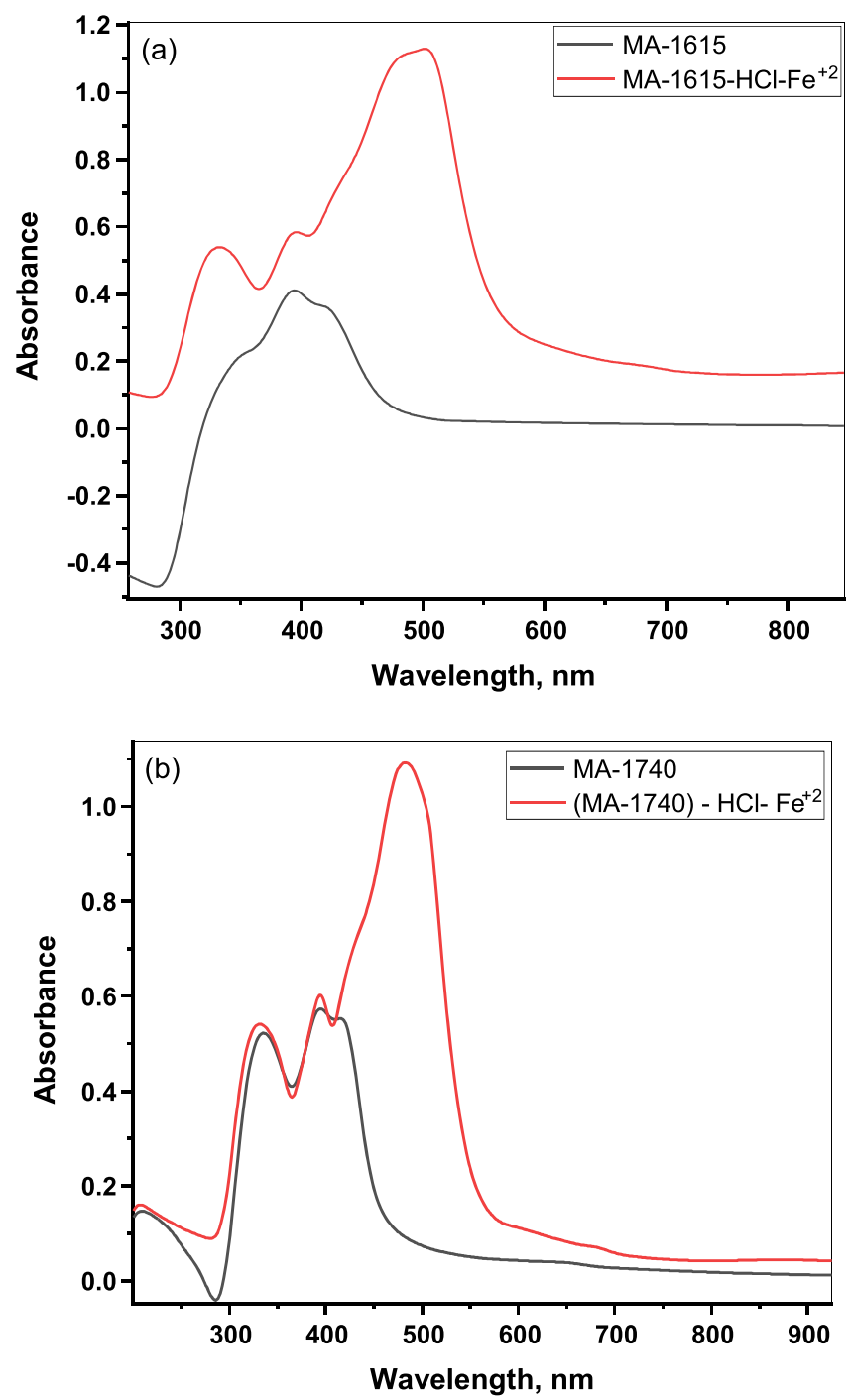

Figure 11. UV-visible electronic spectra of $500 \mu \mathrm{M}$ of inhibitor MA-1615 (a) and inhibitor MA-1740 (b) before (black color) and (red color) after C-steel immersed in $500 \mu \mathrm{M} \mathrm{HCl}$ solution.

the C-steel immersion in the test solution for $28 \mathrm{~h}$ at $30^{\circ} \mathrm{C}$ (Fig. 11a,b) display new visible bands at (501, and $496 \mathrm{~nm}$ ) for MA-1615, and MA-1740, respectively. This confirm the formation of a complex between the Fe $\mathrm{Fe}^{+2}$ cations released during the corrosion reaction and the investigated inhibitors MA-1615, and MA-1740 molecules in $(500 \mu \mathrm{M}) \mathrm{HCl}$ solution ${ }^{55-57}$.

Atomic force microscopic (AFM) analysis. Atomic force microscope (AFM) analysis is a powerful surface analysis technique to assess the morphological surface changes for the used substrate prior to and after the incorporation of corrosion inhibitors in test solutions. Figure 12a-c describes the AFM 3D images of polished $\mathrm{C}$-steel surface and the surface of C-steel after $24 \mathrm{~h}$ immersion in blank $1 \mathrm{M} \mathrm{HCl}$ and another test solution with $0.01 \mathrm{M}$ of inhibitor MA-1740 at room temperature. As shown in Fig. 12a, the API 5L X70 type C-steel before immersion was very smooth and homogeneous surface, while the surface of C-steel after immersion in $1 \mathrm{M} \mathrm{HCl}$ without inhibitor displayed a severely damaged and roughed surface as shown in Fig. 12b. Figure 12c depicts the 3D image of API 5L X70 type C-steel surface in $1 \mathrm{M} \mathrm{HCl}$ solution containing $0.001 \mathrm{M}$ of inhibitor MA-1740 in which the surface has become flatter, and smoother compared to Fig. 12b. This is because the entire surface is insulated by a protective layer of inhibitor MA-1740. From the AFM analysis, the average surface roughness $(R a)$ obtained for the polished C-steel surface was $38.2 \mathrm{~nm}$ and the average surface roughness $(R a)$ of $\mathrm{C}$-steel surface in $1 \mathrm{M} \mathrm{HCl}$ was $467.1 \mathrm{~nm}$ while the $R a$ value in the presence of $0.001 \mathrm{M}$ of MA-1740 was $103.7 \mathrm{~nm}$. These surface roughness values proved that the inhibitor MA-1740 molecules protect the surface of C-steel, most probably by forming a protective film from inhibitor molecules on API 5L X70 C-steel surface ${ }^{58,59}$.

Corrosion inhibition mechanism. The cationic aryl bithiophene/terthiophene derivatives showed outstanding corrosion inhibitive properties which is attributed to the adsorption of these cationic aryl bithiophene/ 


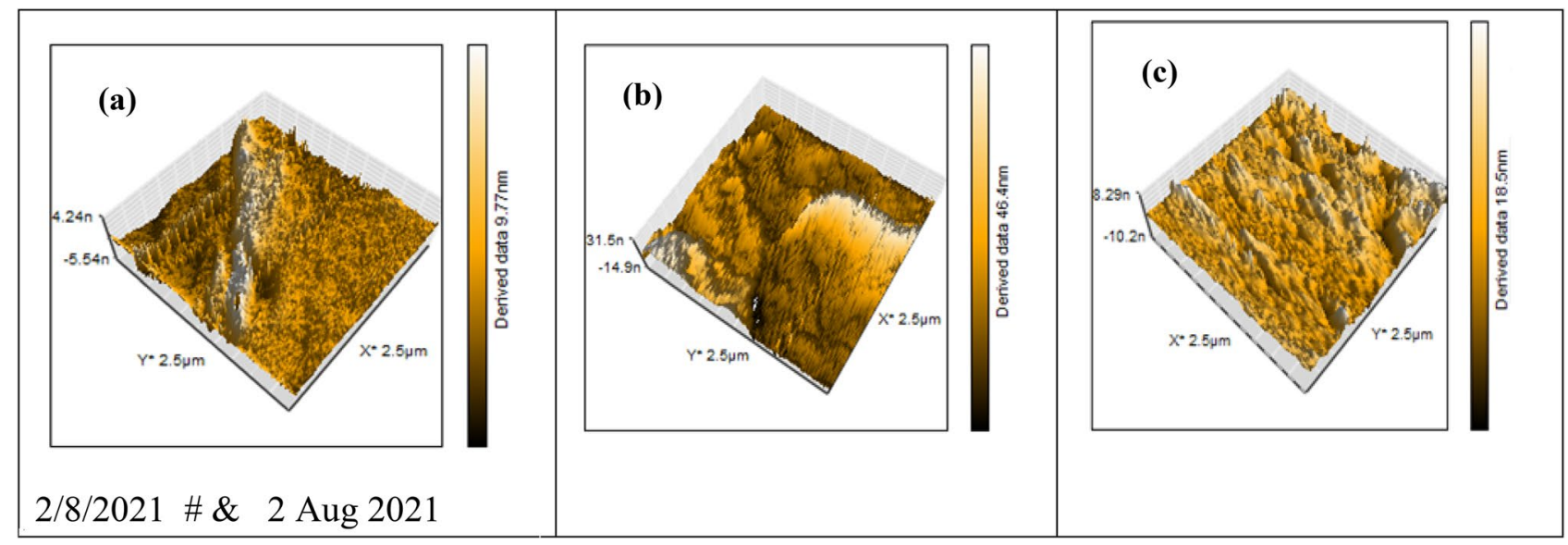

Figure 12. Three-dimensional AFM images for API 5L X70-type C-steel surface in $1 \mathrm{M} \mathrm{HCl:} \mathrm{(a)} \mathrm{before}$ immersion, (b) in $1 \mathrm{M} \mathrm{HCl}$ (Blank) and (c) in $1 \mathrm{M} \mathrm{HCl}$ containing $500 \mu \mathrm{M}$ of inhibitor MA-1740.

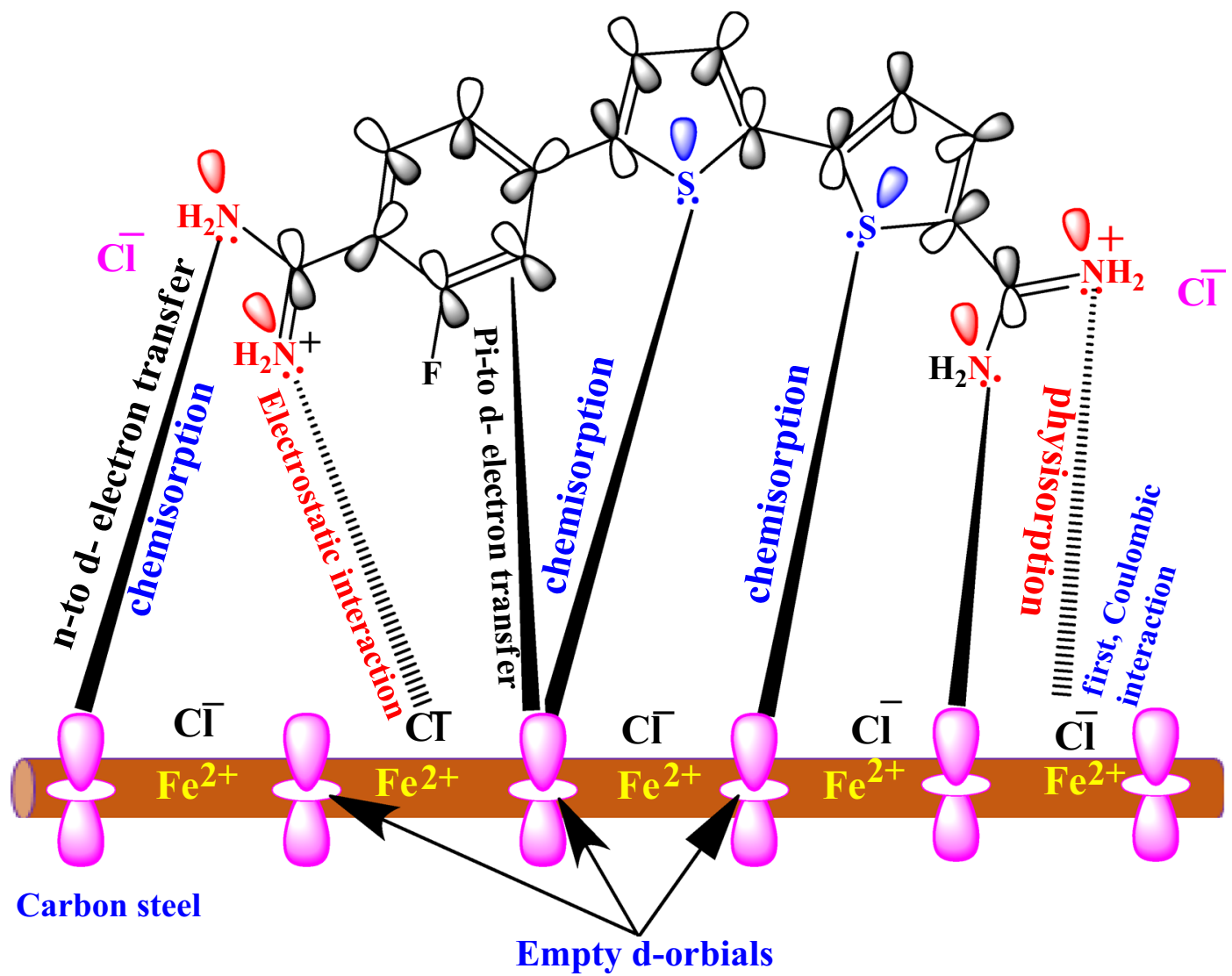

Figure 13. Possible adsorption mechanism of inhibitor MA-1740 on API 5L X70 type C-steel surface in $\mathrm{HCl}$ solution.

terthiophene derivatives on API 5L X70 type C-steel surface in $1 \mathrm{M} \mathrm{HCl}$ through either physisorption or chemisorption type of interaction as presented in Fig. 13. Thiophene rings and nitrogen atoms are considered the active binding sites in the adsorption mechanism. Physisorption involves first the columbic interaction among chloride ions, and then electrostatic interaction takes place between the positively charged $\mathrm{N}$ atoms in inhibitors and the negative charge on the chloride ions that adsorbed to the positively-charger API X70 type C-steel surface in acid solution. This interaction forms a thin barrier layer, inhibiting API X70 C-steel surface from reacting with corrosive species (physical adsorption). Moreover, the existence of chloride anions increases the capacity of adsorption compounds on API X70 C-steel surface ${ }^{3}$. The adsorption of these investigated compounds, on the other hand, can occur chemically onto the steel surface through the high electron density cloud of the $\pi$-electrons aromatic cycles that possess $\mathrm{S}$ heteroatoms, and the imine group $(-\mathrm{C}=\mathrm{N}-)$ that facilitate the extension of the double bond conjugation on the whole structure enhancing the electron distribution and a more pla- 
nar conformation on the substrate surface ${ }^{60}$. The chemical adsorption is also feasible via the coordinating bonds that can be formed between the lone-paint of electron on the heteroatoms $(S)$ of thiophene rings and the vacant $d$-orbitals of Fe atoms in API 5L X70 type C-steel surface ${ }^{61,62}$. The variation between the two inhibitor molecules MA-1740, and MA-1615 in terms of their chemical structure feature was responsible for their different corrosion inhibition performance, as reported throughout all this study. Examining these structural deviations, the MA-1740 molecule possessed two amidine groups and two thiophene rings, and MA-1615 molecule possessed three thiophene rings and one amidine group. Accordingly, these cationic aryl bithiophene/terthiophene derivatives can build up a protective film on the surface of API 5L X70 type C-steel via physical and chemical reactions, protecting the X70 C-steel from further dissolution.

\section{Conclusion}

1. Two novel cationic aryl bithiophene/terthiophene derivatives MA-1615, MA-1740 were synthesized, characterized by spectral means.

2. The new aryl bithiophene/terthiophene derivatives were investigated as corrosion inhibitors in HCl for API 5L X70 C-steel using electrochemical techniques, which showed higher corrosion inhibition action than similar compounds in structure in literature

3. The adsorption of the two investigated cationic inhibitors on API 5L X70 C-steel surface followed Langmuir isotherm and blocking the corrosion reaction sites. The negative sign of $\Delta G_{a d s}^{\circ}$ is an indication that the adsorption of cationic aryl bithiophene/terthiophene derivatives is a spontaneous process. $\Delta G_{a d s}^{\circ}$ values means that the adsorption involves both chemisorption and physisorption mechanisms.

4. Tafel curves indicated that the two investigated cationic inhibitors impede the cathodic and anodic reactions simultaneously, and therefore considered as mixed-type inhibitors. EIS measurements indicate that the increase in the inhibitor's concentration is accompanied with a rise in the values of both $R_{\mathrm{ct}}$ and IE \% and a decline in the value of $C_{\mathrm{dl}}$.

5. AFM pictures confirmed the presence of protective layer on API 5L X70 C-steel surface via the adsorption of the two investigated cationic bithiophene/terthiophene inhibitors. This protective layer protects API 5L X70 steel surface from further acid attack.

6. The presence of dicationic group in MA-1740 has more structural effect on increasing the corrosion inhibition than introducing third thiophene ring.

Received: 15 October 2021; Accepted: 8 February 2022

Published online: 24 February 2022

\section{References}

1. Makhlouf, A. S. H., Herrera, V. \& Muñoz, E. Corrosion and protection of the metallic structures in the petroleum industry due to corrosion and the techniques for protection. In Handbook of Materials Failure Analysis (eds Makhlouf, A. S. H. \& Aliofkhazraei, M.) 107-122 (Elsevier, 2018)

2. Hou, B. et al. The cost of corrosion in China. NPJ Mater. Degrad. 1, 4 (2017).

3. Abousalem, A. S., Ismail, M. A. \& Fouda, A. S. A complementary experimental and in silico studies on the action of fluorophenyl2,2'-bichalcophenes as ecofriendly corrosion inhibitors and biocide agents. J. Mol. Liq. 276, 255-274 (2019).

4. Rbaa, M. et al. New N-heterocyclic compounds based on 8-hydroxyquinoline as efficient corrosion inhibition for mild steel in $\mathrm{HCl}$ solution: Experimental and theoretical assessments. Arab. J. Sci. Eng. 46, 257-274 (2021).

5. Raposo, M. M. M., Fonseca, A. M. C. \& Kirsch, G. Synthesis of donor-acceptor substituted oligothiophenes by Stille coupling. Tetrahedron 60, 4071-4078 (2004).

6. Ismail, M. A., Youssef, M. M., Arafa, R. K., Al-Shihry, S. S. \& El-Sayed, W. M. Synthesis and antiproliferative activity of monocationic arylthiophene derivatives. Eur. J. Med. Chem. 126, 789-798 (2017).

7. Ismail, M. A., Negm, A., Arafa, R. K., Abdel-Latif, E. \& El-Sayed, W. M. Anticancer activity, dual prooxidant/antioxidant effect and apoptosis induction profile of new bichalcophene-5-carboxamidines. Eur. J. Med. Chem. 169, 76-88 (2019).

8. Depauw, S. et al. Heterocyclic diamidine DNA ligands as HOXA9 transcription factor inhibitors: Design, molecular evaluation, and cellular consequences in a HOXA9-dependant leukemia cell model. J. Med. Chem. 62, 1306-1329 (2019).

9. Abdel-Shafi, A. A., Ismail, M. A. \& Al-Shihry, S. S. Effect of solvent and encapsulation in $\beta$-cyclodextrin on the photophysical properties of 4-[5-(thiophen-2-yl) furan-2-yl] benzamidine. J. Photochem. Photobiol. A Chem. 316, 52-61 (2016).

10. Abdel-Shafi, A. A., Fathi, A. M., Ismail, M. A. \& Boykin, D. W. Antiprotozoal agents as water soluble singlet oxygen photosensitizers: Imidazo [1, 2-a] pyridine and 5, 6, 7, 8-tetrahydro-imidazo [1, 2-a] pyridine derivatives. J. Lumin. 181, 164-170 (2017).

11. Dappour, A. M., Taha, M. A., Ismail, M. A. \& Abdel-Shafi, A. A. Solvatochromic behavior of D- $\pi$-A bithiophene carbonitrile derivatives. J. Mol. Liq. 286, 110856 (2019).

12. Sabek, H. A. Z. et al. Photophysical properties and fluorosolvatochromism of D- $\pi-\mathrm{A}$ thiophene based derivatives. RSC Adv. 10, 43459-43471 (2020).

13. Dong, Y., Bolduc, A., McGregor, N. \& Skene, W. G. Push-pull aminobithiophenes highly fluorescent stable fluorophores. Org. Lett. 13, 1844-1847 (2011).

14. Li, Y. et al. Influence of thiophene moiety on the excited state properties of push-pull chromophores. J. Phys. Chem. C 120, $13922-13930$ (2016).

15. Liu, Y., Ye, M., Guo, H.-Z., Zhao, Y.-Y. \& Guo, D.-A. New thiophenes from Echinops grijisii. J. Asian Nat. Prod. Res. 4, 175-178 (2002).

16. Ismail, M. A., Arafa, R. K., Youssef, M. M. \& El-Sayed, W. M. Anticancer, antioxidant activities, and DNA affinity of novel monocationic bithiophenes and analogues. Drug Des. Dev. Ther. 8, 1659 (2014).

17. Perich, M. J., Wells, C., Bertsch, W. \& Tredway, K. E. Isolation of the insecticidal components of Tagetes minuta (Compositae) against mosquito larvae and adults. J. Am. Mosq. Control Assoc. News 11, 307-310 (1995).

18. Fouda, A. S., Ismail, M. A., El-Elewady, G. Y. \& Abousalem, A. S. Evaluation of 4-amidinophenyl-2, 2'-bithiophene and its azaanalogue as novel corrosion inhibitors for CS in acidic media: Experimental and theoretical study. J. Mol. Liq. 240, 372-388 (2017). 
19. Fouda, A. S., Ismail, M. A., Abousalem, A. S. \& Elewady, G. Y. Experimental and theoretical studies on corrosion inhibition of 4-amidinophenyl-2,2'-bifuran and its analogues in acidic media. RSC Adv. 7, 46414-46430 (2017).

20. Fouda, A. S., Ismail, M. A., Temraz, A. M. \& Abousalem, A. S. Comprehensive investigations on the action of cationic terthiophene and bithiophene as corrosion inhibitors: Experimental and theoretical studies. New J. Chem. 43, 768-789 (2019).

21. Hussin, W. A., Ismail, M. A., Alzahrani, A. M. \& El-Sayed, W. M. Evaluation of the biological activity of novel monocationic fluoroaryl-2, 2'-bichalcophenes and their analogues. Drug Des. Dev. Ther. 8, 963 (2014).

22. ASTM International. G3, Standard Practice for Conventions Applicable to Electrochemical Measurements in Corrosion Testing Vol. 3 (ASTM International, 2006).

23. Migahed, M. A., Shaban, M. M., Fadda, A. A., Ali, T. A. \& Negm, N. A. Synthesis of some quaternary ammonium gemini surfactants and evaluation of their performance as corrosion inhibitors for carbon steel in oil well formation water containing sulfide ions. RSC Adv. 5, 104480-104492 (2015).

24. Lebrini, M., Robert, F., Vezin, H. \& Roos, C. Electrochemical and quantum chemical studies of some indole derivatives as corrosion inhibitors for C38 steel in molar hydrochloric acid. Corros. Sci. 52, 3367-3376 (2010).

25. El-Monem, A. M., Shaban, M. M., Migahed, M. A. \& Khalil, M. M. H. Synthesis, characterization, and computational chemical study of aliphatic tricationic surfactants as corrosion inhibitors for metallic equipment in oil fields. ACS Omega 5, 26626-26639 (2020).

26. Verma, C., Olasunkanmi, L. O., Ebenso, E. E. \& Quraishi, M. A. Substituents effect on corrosion inhibition performance of organic compounds in aggressive ionic solutions: A review. J. Mol. Liq. 251, 100-118 (2018).

27. Chidiebere, M. A., Ogukwe, C. E., Oguzie, K. L., Eneh, C. N. \& Oguzie, E. E. Corrosion inhibition and adsorption behavior of Punica granatum extract on mild steel in acidic environments: Experimental and theoretical studies. Ind. Eng. Chem. Res. 51, 668-677 (2012).

28. Shaban, M. M. et al. Novel trimeric cationic pyrdinium surfactants as bi-functional corrosion inhibitors and antiscalants for API 5L X70 carbon steel against oilfield formation water. J. Mol. Liq. 305, 112817 (2020).

29. Singh, A., Ansari, K. R., Quraishi, M. A. \& Kaya, S. Theoretically and experimentally exploring the corrosion inhibition of N80 steel by pyrazol derivatives in simulated acidizing environment. J. Mol. Struct. 1206, 127685 (2020).

30. Yüce, A. O. \& Kardaş, G. Adsorption and inhibition effect of 2-thiohydantoin on mild steel corrosion in $0.1 \mathrm{M} \mathrm{HCl}$. Corros. Sci. 58, 86-94 (2012).

31. Ouakki, M. et al. Investigation of imidazole derivatives as corrosion inhibitors for mild steel in sulfuric acidic environment: Experimental and theoretical studies. Ionics (Kiel) 26, 5251-5272 (2020).

32. Rouifi, Z. et al. Synthesis, characterization and corrosion inhibition potential of newly benzimidazole derivatives: Combining theoretical and experimental study. Surf. Interfaces 18, 100442 (2020).

33. Alaoui, K. et al. Molecular dynamics, Monte-Carlo Simulations and atomic force microscopy to study the interfacial adsorption behaviour of some triazepine carboxylate compounds as corrosion inhibitors in acid medium. J. Bio Tribo-Corros. 5, 1 (2019).

34. Saranya, J. et al. N-heterocycles as corrosion inhibitors for mild steel in acid medium. J. Mol. Liq. 216, 42-52 (2016).

35. Deng, S., Li, X. \& Xie, X. Hydroxymethyl urea and 1, 3-bis (hydroxymethyl) urea as corrosion inhibitors for steel in $\mathrm{HCl}$ solution. Corros. Sci. 80, 276-289 (2014).

36. Farag, A. A., Eid, A. M., Shaban, M. M., Mohamed, E. A. \& Raju, G. Integrated modeling, surface, electrochemical, and biocidal investigations of novel benzothiazoles as corrosion inhibitors for shale formation well stimulation. J. Mol. Liq. 336, 116315 (2021).

37. Daoud, D., Douadi, T., Issaadi, S. \& Chafaa, S. Adsorption and corrosion inhibition of new synthesized thiophene Schiff base on mild steel X52 in HCl and H2SO4 solutions. Corros. Sci. 79, 50-58 (2014).

38. Bayol, E., Gürten, T., Gürten, A. A. \& Erbil, M. Interactions of some Schiff base compounds with mild steel surface in hydrochloric acid solution. Mater. Chem. Phys. 112, 624-630 (2008).

39. Mert, B. D., Yüce, A. O., Kardaş, G. \& Yazıc1, B. Inhibition effect of 2-amino-4-methylpyridine on mild steel corrosion: Experimental and theoretical investigation. Corros. Sci. 85, 287-295 (2014).

40. Zhang, H. H. \& Chen, Y. Experimental and theoretical studies of benzaldehyde thiosemicarbazone derivatives as corrosion inhibitors for mild steel in acid media. J. Mol. Struct. 1177, 90-100 (2019).

41. Negm, N. A. et al. High performance corrosion inhibition of novel tricationic surfactants on carbon steel in formation water: Electrochemical and computational evaluations. J. Mol. Liq. 262, 363-375 (2018).

42. Nam, N. D., Bui, Q. V., Mathesh, M., Tan, M. Y. J. \& Forsyth, M. A study of 4-carboxyphenylboronic acid as a corrosion inhibitor for steel in carbon dioxide containing environments. Corros. Sci. 76, 257-266 (2013).

43. Migahed, M. A., Farag, A. A., Elsaed, S. M., Kamal, R. \& El-Bary, H. A. Corrosion inhibition of steel pipelines in oil well formation water by a new family of nonionic surfactants. Chem. Eng. Commun. 199, 1335-1356 (2012).

44. Kosari, A. et al. Electrochemical and quantum chemical assessment of two organic compounds from pyridine derivatives as corrosion inhibitors for mild steel in $\mathrm{HCl}$ solution under stagnant condition and hydrodynamic flow. Corros. Sci. 78, 138-150 (2014).

45. Migahed, M. A., Zaki, E. G. \& Shaban, M. M. Corrosion control in the tubing steel of oil wells during matrix acidizing operations. RSC Adv. 6, 71384-71396 (2016).

46. Kıcır, N., Tansuğ, G., Erbil, M. \& Tüken, T. Investigation of ammonium (2, 4-dimethylphenyl)-dithiocarbamate as a new, effective corrosion inhibitor for mild steel. Corros. Sci. 105, 88-99 (2016).

47. El-Defrawy, A. M., Abdallah, M. \& Al-Fahemi, J. H. Electrochemical and theoretical investigation for some pyrazolone derivatives as inhibitors for the corrosion of C-steel in $0.5 \mathrm{M}$ hydrochloric acid. J. Mol. Liq. 288, 110994 (2019).

48. Olasunkanmi, L. O., Sebona, M. F. \& Ebenso, E. E. Influence of 6-phenyl-3 (2H)-pyridazinone and 3-chloro-6-phenylpyrazine on mild steel corrosion in $0.5 \mathrm{M} \mathrm{HCl}$ medium: Experimental and theoretical studies. J. Mol. Struct. 1149, 549-559 (2017).

49. Tourabi, M., Nohair, K., Traisnel, M., Jama, C. \& Bentiss, F. Electrochemical and XPS studies of the corrosion inhibition of carbon steel in hydrochloric acid pickling solutions by 3,5-bis(2-thienylmethyl)-4-amino-1,2,4-triazole. Corros. Sci. 75, 123-133 (2013).

50. Solmaz, R. Investigation of adsorption and corrosion inhibition of mild steel in hydrochloric acid solution by 5-(4-Dimethylaminobenzylidene)rhodanine. Corros. Sci. 79, 169-176 (2014).

51. Abdallah, M., Al-Tass, H. M., Jahdaly, B. A. A. L. \& Fouda, A. S. Inhibition properties and adsorption behavior of 5-arylazothiazole derivatives on 1018 carbon steel in 0.5 M H2SO4 solution. J. Mol. Liq. 216, 590-597 (2016).

52. Rbaa, M. et al. Two new 8-hydroxyquinoline derivatives as an efficient corrosion inhibitors for mild steel in hydrochloric acid: Synthesis, electrochemical, surface morphological, UV-visible and theoretical studies. J. Mol. Liq. 276, 120-133 (2019).

53. Fouda, A. S., El-Haddad, M. N., Ismail, M. A. \& Abd Elgyed, A. Investigation of 6-[5-(4-Methoxyphenyl) furan-2-yl] Nicotinonitrile as a new corrosion inhibitor for carbon steel in acidic solution: Chemical, electrochemical and quantum chemical studies. J. Bio Tribo-Corros. 5, 1-14 (2019).

54. Umoren, S. A. Polypropylene glycol: A novel corrosion inhibitor for $\times 60$ pipeline steel in $15 \% \mathrm{HCl}$ solution. J. Mol. Liq. 219, 946-958 (2016).

55. El-Haddad, M. N. Hydroxyethylcellulose used as an eco-friendly inhibitor for $1018 \mathrm{c}$-steel corrosion in $3.5 \% \mathrm{NaCl}$ solution. Carbohydr. Polym. 112, 595-602 (2014).

56. Yadav, D. K. \& Quraishi, M. A. Application of some condensed uracils as corrosion inhibitors for mild steel: Gravimetric, electrochemical, surface morphological, UV-visible, and theoretical investigations. Ind. Eng. Chem. Res. 51, 14966-14979 (2012).

57. Fiori-Bimbi, M. V., Alvarez, P. E., Vaca, H. \& Gervasi, C. A. Corrosion inhibition of mild steel in HCL solution by pectin. Corros. Sci. 92, 192-199 (2015). 
58. Verma, C. et al. Experimental, density functional theory and molecular dynamics supported adsorption behavior of environmental benign imidazolium based ionic liquids on mild steel surface in acidic medium. J. Mol. Liq. 273, 1-15 (2019).

59. Dehghani, A., Bahlakeh, G., Ramezanzadeh, B. \& Ramezanzadeh, M. Potential of Borage flower aqueous extract as an environmentally sustainable corrosion inhibitor for acid corrosion of mild steel: Electrochemical and theoretical studies. J. Mol. Liq. 277, 895-911 (2019).

60. Murmu, M., Saha, S. K., Murmu, N. C. \& Banerjee, P. Effect of stereochemical conformation into the corrosion inhibitive behaviour of double azomethine based Schiff bases on mild steel surface in $1 \mathrm{~mol} \mathrm{~L}-1 \mathrm{HCl}$ medium: An experimental, density functional theory and molecular dynamics simulation study. Corros. Sci. 146, 134-151 (2019).

61. Zhang, Q. B. \& Hua, Y. X. Corrosion inhibition of mild steel by alkylimidazolium ionic liquids in hydrochloric acid. Electrochim. Acta 54, 1881-1887 (2009).

62. Hussien, B. M., Al-Sabagh, A. M., Migahed, M. A., Shaban, M. M. \& Moawad, Z. Corrosion control of X-60 type carbon steel in petroleum formation water under high pressure of $\mathrm{CO} 2$ at high temperature. In Offshore Mediterranean Conference and Exhibition (OnePetro, 2017).

\section{Acknowledgements}

The authors are greatly thankful to Mansoura University and the Egyptian Petroleum Research Institute (EPRI) for research facilities.

\section{Author contributions}

M.A.I. and E.A.-L. supervised the preparation and characterization of the new compounds, M.M.S. did the electrochemical experiments, calculations, and drafting of the electrochemical study part. F.H.A. prepared the new compounds and contributed to the characterization part. M.A.M. supervised the electrochemical testing and contributed to reviewing the paper. M.N.E.-H. did the UV study. M.A.I. and A.S.A. provided the concept and wrote the paper. All authors reviewed the manuscript.

\section{Funding}

Open access funding provided by The Science, Technology \& Innovation Funding Authority (STDF) in cooperation with The Egyptian Knowledge Bank (EKB).

\section{Competing interests}

The authors declare no competing interests.

\section{Additional information}

Supplementary Information The online version contains supplementary material available at https://doi.org/ 10.1038/s41598-022-06863-8.

Correspondence and requests for materials should be addressed to M.A.I. or A.S.A.

Reprints and permissions information is available at www.nature.com/reprints.

Publisher's note Springer Nature remains neutral with regard to jurisdictional claims in published maps and institutional affiliations.

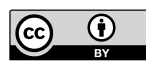

Open Access This article is licensed under a Creative Commons Attribution 4.0 International License, which permits use, sharing, adaptation, distribution and reproduction in any medium or format, as long as you give appropriate credit to the original author(s) and the source, provide a link to the Creative Commons licence, and indicate if changes were made. The images or other third party material in this article are included in the article's Creative Commons licence, unless indicated otherwise in a credit line to the material. If material is not included in the article's Creative Commons licence and your intended use is not permitted by statutory regulation or exceeds the permitted use, you will need to obtain permission directly from the copyright holder. To view a copy of this licence, visit http://creativecommons.org/licenses/by/4.0/.

(C) The Author(s) 2022 